Prepared for the U.S. Department of Energy

under Contract DE-AC05-76RL01830

\title{
Behavioral Change and Building Performance: Strategies for Significant, Persistent, and Measurable Institutional Change
}

\author{
AK Wolfe \\ EL Malone \\ $\mathrm{J}$ Heerwagen \\ J Dion
}

April 2014

Pacific Northwest

NATIONAL LABORATORY

Proudly Operated by Battelle Since 1965 


\title{
DISCLAIMER
}

This report was prepared as an account of work sponsored by an agency of the United States Government. Neither the United States Government nor any agency thereof, nor Battelle Memorial Institute, nor any of their employees, makes any warranty, express or implied, or assumes any legal liability or responsibility for the accuracy, completeness, or usefulness of any information, apparatus, product, or process disclosed, or represents that its use would not infringe privately owned rights. Reference herein to any specific commercial product, process, or service by trade name, trademark, manufacturer, or otherwise does not necessarily constitute or imply its endorsement, recommendation, or favoring by the United States Government or any agency thereof, or Battelle Memorial Institute. The views and opinions of authors expressed herein do not necessarily state or reflect those of the United States Government or any agency thereof.

\author{
PACIFIC NORTHWEST NATIONAL LABORATORY \\ operated by \\ BATTELLE \\ for the \\ UNITED STATES DEPARTMENT OF ENERGY \\ under Contract DE-AC05-76RL01830
}

Printed in the United States of America

Available to DOE and DOE contractors from the

Office of Scientific and Technical Information,

P.O. Box 62, Oak Ridge, TN 37831-0062;

ph: (865) 576-8401

fax: $(865) 576-5728$

email: reports@adonis.osti.gov

Available to the public from the National Technical Information Service

5301 Shawnee Rd., Alexandria, VA 22312

ph: (800) 553-NTIS (6847)

email: orders@intis.gov $<$ http://www.ntis.gov/about/form.aspx $>$

Online ordering: http://www.ntis.gov

This document was printed on recycled paper. 


\title{
Behavioral Change and Building Performance: Strategies for Significant, Persistent, and Measurable Institutional Change
}

\author{
AK Wolfe ${ }^{1}$ \\ EL Malone \\ $\mathrm{J}$ Heerwagen ${ }^{2}$ \\ J Dion ${ }^{3}$
}

April 2014

Prepared for

the U.S. Department of Energy

under Contract DE-AC05-76RL01830

Pacific Northwest National Laboratory

Richland, Washington 99352

\footnotetext{
${ }^{1}$ Oak Ridge National Laboratory, Oak Ridge, Tennessee.

${ }^{2}$ General Services Administration, Seattle, Washington

${ }^{3}$ U.S. Department of Energy, Federal Energy Management Program, Washington, D.C.
} 



\section{Summary}

The people who use Federal buildings - Federal employees, operations and maintenance staff, and the general public - can significantly impact a building's environmental performance and the consumption of energy, water, and materials. Many factors influence building occupants' use of resources (use behaviors) including work process requirements, ability to fulfill agency missions, new and possibly unfamiliar high-efficiency/high-performance building technologies; a lack of understanding, education, and training; inaccessible information or ineffective feedback mechanisms; and cultural norms and institutional rules and requirements, among others. While many strategies have been used to introduce new occupant use behaviors that promote sustainability and reduced resource consumption, few have been verified in the scientific literature or have properly documented case study results.

This paper documents validated strategies that have been shown to encourage new use behaviors that can result in significant, persistent, and measureable reductions in resource consumption. From the peerreviewed literature, the paper identifies relevant strategies for Federal facilities and commercial buildings that focus on the individual, groups of individuals (e.g., work groups), and institutions - their policies, requirements, and culture. The paper documents methods with evidence of success in changing use behaviors and enabling occupants to effectively interact with new technologies/designs. It also provides a case study of the strategies used at a Federal facility - Fort Carson, Colorado. The paper documents gaps in the current literature and approaches, and provides topics for future research.

Institutional context, composed of three major elements (rules, roles, and tools), frames the strategies and actions that drive significant and enduring reductions in energy, water, and material use. New approaches must use evidence-based principles and apply proven behavioral change strategies that align with the behaviors and cultures at multiple levels within the organization and that are best suited for achieving specific energy- or sustainability-related goals. The key strategies for promoting behavioral change evident in peer-reviewed literature include

- Providing Information and Outreach

- Giving Feedback

- Persuading

- Offering Rewards and Incentives

- Changing Defaults, Nudging Choice, and Enabling Adaptive Comfort

- Gaining Commitment

- Tapping into Social Norms

- Social Marketing in Communities

- Responding to an Urgent Situation.

Initiating change is different from maintaining or improving upon those changes over time. Ensuring sustained change requires an adaptive approach that (1) leverages successes, (2) updates and embeds formal and informal organizational rules to support sustainable resource use, and (3) strategically promotes change in organizational culture driven by leaders and others playing key roles in the organization. 
This paper provides the evidentiary and conceptual background for selecting proven context- and goal-specific behavioral change strategies, and highlights potential opportunities for Federal agencies and the commercial building sector. The discussion employs a "systems perspective" of occupant use behaviors to drive broad organizational transformation in support of sustainability and improved building performance. The objective is to elucidate potential strategies to achieve improved building performance within the context of the organization and its culture - behavior and behavior change aim to enable these outcomes and are not ends in themselves nor mandated by Federal requirements.

The paper makes the following high-level recommendations for implementing an action-based framework for changing individual and organizational use behaviors and achieving organizational sustainability and building performance goals:

1. Adopt a systems perspective to assess, design, implement, and evaluate sustainability and resource use strategies and programs as integrated technological and use activities.

2. Employ multiple methods and strategies that are supported by peer-reviewed scientific research as effective and aligned with specific sustainability goals and with mission fulfillment.

3. Promote an enduring institutional transformation by evaluating outcomes to determine what strategies work best to promote and reinforce a culture of sustainability, what strategies are not effective and should be discontinued, and what strategies should be revised.

4. Sponsor social science research that will build the evidence base for behavioral and institutional strategies aimed at saving energy, water, and materials, and at operating buildings sustainably over the long term.

Unless new technologies, occupant use behaviors, and institutional rules and requirements are integrated to complement new stringent Federal building performance requirements, suboptimal outcomes will limit Federal agencies' abilities to achieve their sustainability and building performance goals and objectives now and in the future. 


\section{Acronyms and Abbreviations}

$\begin{array}{ll}\text { BEM } & \text { Building Energy Monitor } \\ \text { BTRD Subcommittee } & \text { Buildings Technology Research and Development Subcommittee } \\ \text { CBSM } & \text { Community Based Social Marketing } \\ \text { CFL } & \text { Compact Fluorescent Lamp } \\ \text { DOD } & \text { U.S. Department of Defense } \\ \text { DOE } & \text { U.S. Department of Energy } \\ \text { GHG } & \text { Greenhouse Gas } \\ \text { NSTC } & \text { U.S. National Science and Technology Council } \\ \text { O\&M } & \text { Operations and Maintenance } \\ \text { OSTP } & \text { U.S. Office of Science and Technology Policy }\end{array}$





\section{Contents}

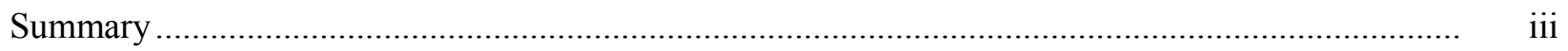

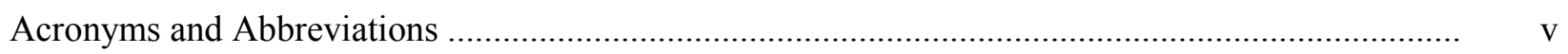

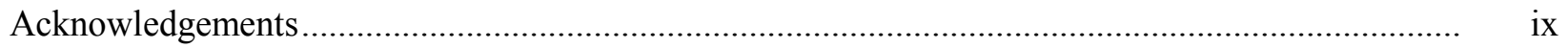

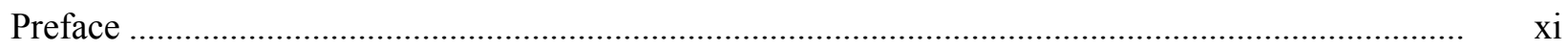

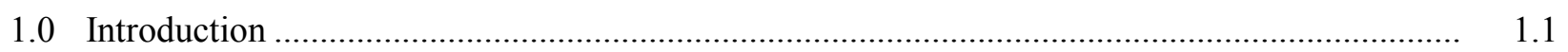

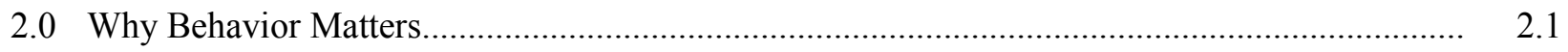

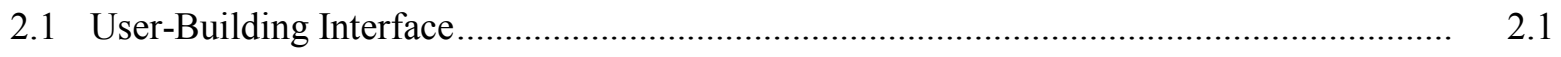

2.2 Individual Behaviors and Norms......................................................................... 2.2

2.3 Sustainability Efforts in Federal Buildings .............................................................. 2.2

3.0 Linking Behavioral and Organizational Change to Achieve Sustainability Goals.................... 3.1

3.1 Definitions of Behavior, Behavior Change, and Building Operational Performance .......... 3.1

3.2 Buildings as the Locus of Behavior ........................................................................... 3.2

3.3 The Dynamics of Occupants in Buildings................................................................... 3.4

4.0 Rules, Roles, and Tools: Using Knowledge of Institutional Context as a Basis for Taking

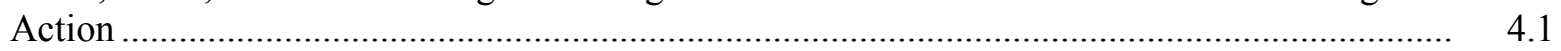

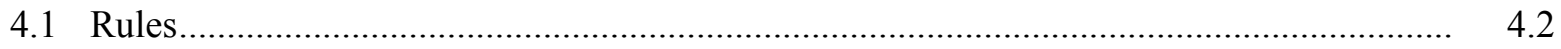

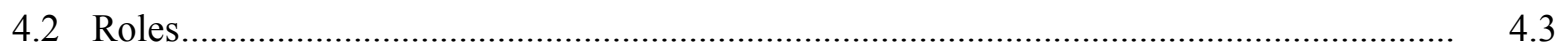

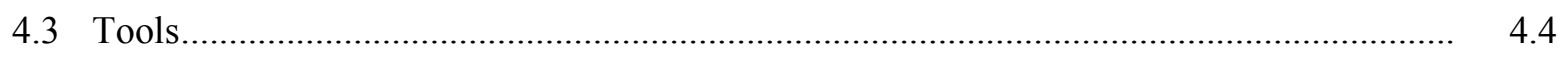

4.4 Strategies to Prompt and Sustain Change ................................................................... 4.5

5.0 Strategic and Specific Methods to Achieving Behavioral and Institutional Change.................. 5.1

5.1 About Peer-Reviewed Behavioral Change Literature ................................................... 5.1

5.2 Providing Information and Outreach........................................................................ 5.1

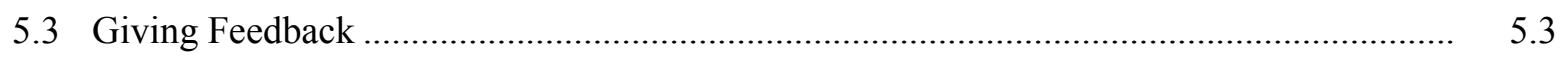

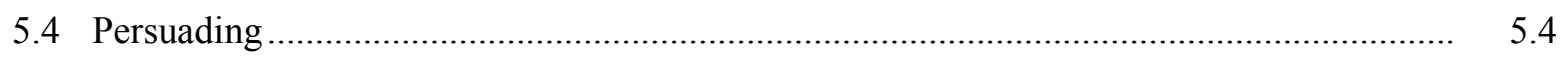

5.5 Offering Rewards and Incentives ........................................................................... 5.5

5.6 Changing Defaults, Nudging Choice, and Enabling Adaptive Comfort ........................... 5.6

5.7 Gaining Commitment ........................................................................................ 5.7

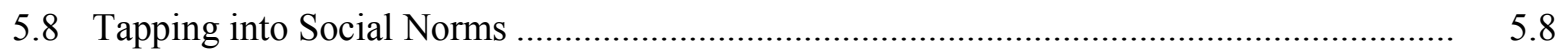

5.9 Social Marketing in Communities........................................................................... 5.8

5.10 Responding to an Urgent Situation ...................................................................... 5.9

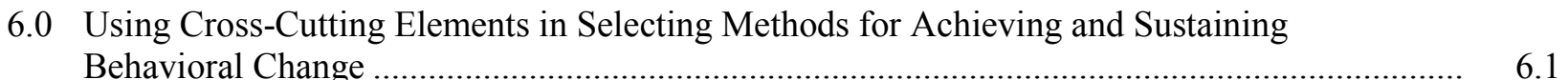

6.1 Establishing Habits that Foster Sustainability ............................................................ 6.1

6.2 Appealing to Multiple Motivations ................................................................................. 6.2

6.3 Achieving Broad and Persistent Impacts over Time ...................................................... 6.3

7.0 Testing the Rules, Roles, and Tools Construct.................................................................

8.0 Recommendations for an Action-Focused Framework ................................................... 
9.0 Research and Development Agenda for Institutional Change in Buildings ............................ 9.1

Appendix A - Subcommittee on Buildings Technology Research and Development ....................... A.1

Appendix B - Testing the "Rules, Roles, and Tools" Construct .................................................... B.1

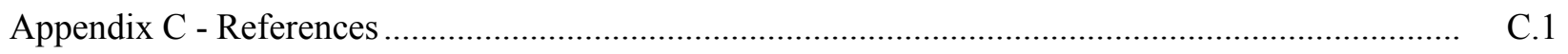




\section{Acknowledgements}

This paper was prepared by Amy K. Wolfe, Judith Heerwagen, Elizabeth L. Malone, and Jerome Dion. In addition to the principal authors of this paper, substantial assistance was provided by Paul Domich. Significant review and advice was provided by many members of the Buildings Technology Research and Development Subcommittee of the National Science and Technology Council. 



\section{Preface}

The construction and buildings sector consumes enormous amounts of energy, clean water, and materials. Buildings use about one-third of the world's energy. In the United States today, the buildings sector accounts for 40 percent of the primary energy use, compared to 32 percent for the industrial sector and 28 percent for the transportation sector. The use of electric power and heat in the buildings sector also accounts for about 40 percent of U.S. greenhouse gas (GHG) emissions. Advances in water- and energyefficient technologies hold the promise to significantly reduce resource consumption in buildings.

However, history repeatedly has shown a gap between potential and actual energy, water, and material savings in buildings - a gap often associated with the behavior of building operators and occupants. Further, many proposed strategies for changing behavior to reduce resource consumption are unverified and their outcomes are undocumented. For the Nation to significantly decrease its energy, water, and material consumption in buildings, a combination of new technologies and proven strategies for changing occupant and organizational use practices is required.

Responding to this need, this paper offers strategies and methods for change at individual, organizational, and institutional levels of action to reduce energy, water and materials consumption. The paper communicates some of the best practices examined by the Buildings Technology Research and Development (BTRD) Subcommittee of the Committee on Technology (COT), National Science and Technology Council (NSTC) and presents a framework for integrating human behavior, organizational practices, and building operations to enhance overall building performance. The paper is intended for Federal executives, program managers, sustainability officers, and procurement and human resource specialists with responsibility to achieve Federal building performance and sustainability requirements. The framework applies in principle to Federal and commercial office, laboratory, and other nonresidential buildings designed for occupant use. 



\subsection{Introduction}

Architects and engineers design and retrofit Federal buildings to achieve increasingly aggressive environmental goals and mandates using a broad range of advanced technologies and design strategies. These technologies and designs, for new and retrofitted high-performance buildings, may perform well in theory — based upon analytical building models and simulations. Once the building is completed and occupants move in, however, the actual performance often runs contrary to expectations. While some high-performance buildings achieve their environmental performance goals, many do not (Turner and Frankel 2008, Cole 2011). History repeatedly has shown a gap between potential and actual energy savings, a gap often associated with the behavior of people who manage and use buildings and building systems.

Increasing evidence (e.g., Stern 2002, Janda 2014) suggests that the everyday behaviors of building occupants and standard operating procedures of organizations are a much-overlooked factor in achieving building performance goals and the conservation of resources (energy, water, materials). Included in these everyday behaviors are standard (and substandard) building operating procedures, occupant use (and misuse) of building resources and technologies, and outdated organizational practices and cultural norms. For office buildings, the number of miscellaneous devices plugged into electrical outlets continues to rise and represents the single fastest-growing category for electrical consumption in buildings. When combined with an ever-increasing reliance on other energy-intensive technologies and equipment (e.g., computer servers, high-quality printers) to carry out agency mission requirements, occupant use behaviors make conserving resources and improving building performance an increasingly important and challenging endeavor. Janda (2014) suggests that the "social potential" of energy efficiency in workplaces is as or more important than the "technical potential" usually measured - but that an approach integrating the two would have the largest impact (Shui 2012, Moezzi and Janda 2013).

This paper, commissioned by the former Behavioral Task Group for the Buildings Technology Research and Development Subcommittee of the National Science and Technology Council, provides a framework for integrating human behavior, organizational practices, and building operations to enhance overall building performance. It offers strategies and methods for change at the individual, organizational, and institutional levels. Section 2 reviews the importance of a focus on human-centered change, followed by an overview of ways to think about energy use and behavioral change in buildings (Section 3 ). Section 4 uses a construct of "rules, roles, and tools" as to guide the assessment of institutional context and as a basis for selecting strategies that are effective for achieving and maintaining behavioral and institutional change. Sections 5 and 6 take a closer look at successful approaches for changing use behaviors, and Section 7 presents a case study of behavioral change in a Federal facility. The paper's conclusions (Sections 8 and 9), make recommendations for an action-oriented framework for improving use behavior in buildings, and for an R\&D agenda aimed at deepening the understanding of sustainability-oriented behavior and behavioral change to make programs for significant, persistent change more effective. 



\subsection{Why Behavior Matters}

Understanding behavior is crucial in determining the extent to which performance goals embedded in building design and technologies actually are achieved. Building occupants are seldom trained or well informed about building systems operation and how their behaviors, individually and collectively, affect a building's environmental performance. Building operations and maintenance (O\&M) staff may not have adequate training to properly operate new, high-performance, energy-efficient building systems. Furthermore, interventions designed to improve building performance are often implemented piecemeal, focusing on a single component and target audience at a time rather than viewing the building and its occupants ${ }^{1}$ as an integrated whole (i.e., a systems view) with varying needs and space types, technologies, and workplace responsibilities and practices. Building technologies designed to reduce resource consumption must therefore be complemented by appropriate use behaviors by O\&M staff and occupants. Identifying effective combinations of technologies and behaviors can reduce resource consumption resulting in lower facility operational costs.

Theory - supported by scientific research — indicates that behavior can play a substantial role in reducing greenhouse gas (GHG) emissions and energy use (Dietz et al. 2009). However, despite recent interest in and efforts to realize this potential, results have been both disappointing (i.e., not meeting aspirational goals) and lacking in the kinds of evidence that could guide future efforts (i.e., without the basis for confident replication) (Lenoir et al. 2011, Hauge et al. 2010). ${ }^{2}$ In the absence of coherent and well-documented approaches to changing behavior and organizational change management, there has been a burgeoning interest in exploring new approaches. A negative consequence of such activity is that untested and potentially ineffective strategies may be adopted, resulting in suboptimal outcomes that can discourage building owners, managers, and occupants from embracing future sustainability initiatives.

\subsection{User-Building Interface}

The importance of behavioral change is evident in that building systems using new high-performance technologies often fail to meet their "as designed" performance expectations (Turner and Frankel 2008). At least part of this performance gap is likely attributable to a mismatch between the building's design elements and the users' needs - the user-building interface - as well as to occupants' unforeseen uses of the building systems and technologies. As noted by Turner and Frankel, the highest energy use buildings are "driven by requirements and process loads of occupant activities as opposed to basic building systems." For Federal agencies these "occupant activities" can be characterized as missionrelevant.

At the present time, designers and operators often do not adequately address the user-building interface. This omission has significant consequences for how buildings are designed and equipped, how well buildings achieve sustainability goals, and how building systems can affect the work environment and occupant comfort levels. For energy performance goals, the problem is exacerbated by the fact that

\footnotetext{
1 "Occupants" include organizations and all individuals associated with the organization. Some organizational actors may not actually work within a particular building, yet have great influence over energy-use behaviors within the building.

${ }^{2}$ The disappointing results for energy efficiency initiatives are a specific example of the general disappointing results of corporate change initiatives (see Aiken and Keller 2009).
} 
"energy is not consumed directly, but rather as a means to achieve specific goals" which include comfortable temperatures, sufficient light, and the ability to use computers and other electronic equipment necessary for work (Aune et al. 2009). Thus, the building occupant's perspective on energy consumption is not about energy per se, but the capabilities it provides for achieving job and mission goals. Deep, sustained changes in occupant use behavior require a systematic, well-designed approach more than the simple "competitions," lobby energy displays, or desktop dashboards currently in vogue. As this paper demonstrates, persistent and transformative change is built upon a strategic approach involving multiple and continuing change efforts throughout the organization and a rethinking of the userbuilding interface (Moezzi and Janda 2013, Cole 2011).

\subsection{Individual Behaviors and Norms}

Human behavior is an essential and frequently overlooked element in achieving aggressive Federal building performance goals, especially for reducing consumption of energy, water, and materials. Building technologies are increasingly effective at reducing resource consumption, but occupant routines, habits, and choices can significantly impact the building's overall performance. These behaviors include many habitual actions (e.g., turning off equipment when not being used, routine building system O\&M procedures) as well as complex behaviors, such as procurement or contracting procedures, required to implement policies that affect high-impact outcomes (mission, energy use, and so on). Some behaviors may be episodic, e.g., responding to emergency conditions such as rolling brownouts or water shortages. Other behaviors may involve a suite of actions that drive sustainability across the organization through changes in roles, responsibilities, and ways of thinking. Deep, sustained change at the individual level is more difficult to achieve and requires a programmatic focus and significant effort for perhaps several years until new norms become embedded as "how things are done" in the organization.

\subsection{Sustainability Efforts in Federal Buildings}

In the Federal sector, new governmental rules contained in Presidential Executive Orders, Office of Management and Budget (OMB) Circulars, and statutory requirements are driving Federal sustainability efforts. Of these, the Energy Independence and Security Act of 2007 (EISA 2007) requires agencies to establish and report on increasingly aggressive sustainability and performance goals on an annual basis. To meet these goals, institutional procedures governing internal Federal agency operations, mission requirements, personnel roles and responsibilities, contracts, and procurements must now align with these new directives and annual goals. Moreover, institutional change must be aligned with the desired behavioral change throughout the workplace. Without these alignments, suboptimal outcomes will occur and hinder Federal agencies' abilities to achieve their mandated sustainability goals and objectives.

Federal agencies are now implementing strategies for achieving far-reaching sustainability goals, including increasing energy and water efficiency; reducing GHG emissions, waste, and pollution; and more effectively managing information technology resources. The growing recognition in the Federal community is that achieving these goals will involve large-scale technological change and significant behavioral changes at the individual, organizational, and institutional levels. New strategies must be identified that effectively integrate these technology and behavioral elements. Such strategies will produce better results than either technological or behavioral strategies by themselves (Shui 2012), reorienting occupants in their various rules of operation, roles, technologies, and infrastructure to ensure a continuous process of becoming more sustainable. The desired outcome is transformational, persistent 
change manifested in significant progress toward established goals in all sustainability and building performance categories. Successes in the Federal sector can then be shared with other important building subsectors: commercial office and other nonresidential buildings. 



\subsection{Linking Behavioral and Organizational Change to Achieve Sustainability Goals}

This paper provides an integrative approach linking traditional and emerging behavioral change methods at individual and group levels with methods and best practices for organizational change. Most behavioral change efforts focus on either individual or organizational change and omit the synergy that results from the combination of approaches. Given the breadth of behaviors and practices that need to change to achieve deep and lasting sustainability in an organization, narrowly focused, short-term efforts will not meet current or future sustainability goals and requirements. To begin this analysis, definitions are given that will be used throughout and provide context for the discussion, followed by sections on buildings as the locus of behavior and the dynamics of building occupants.

\subsection{Definitions of Behavior, Behavior Change, and Building Operational Performance}

Behavior includes how people and organizations act, how they function (patterns of action and interaction over time, sometimes referred to as institutional behavior), and what choices they make whether in response to internal/external stimuli, or in anticipation of future events/conditions, out of subconscious habit, or for no immediately apparent reason.

Responding to an internal stimulus of feeling too warm, for example, may lead to opening a window, turning a thermostat down, or using an electrical fan. Responding to an external stimulus would be closing the window blinds to avoid glare. External stimuli can also be non-physical, such as a new rule or procedure that directs people to respond in a new way (such as turning their computers off at night). In addition, individuals respond to non-energy, non-resource stimuli and situations in ways that have significant impacts on resource consumption. They use high-quality printers, copiers, and video conferencing equipment to increase their productivity as well as espresso nooks, refrigerators, and microwaves to create more pleasant work environments. At an organizational level, people act in response to their job responsibilities (e.g., procurement versus maintenance versus administrative), which, in turn, are affected by a wide variety of expectations and stimuli.

Behavior change refers to alterations in patterns of action and choices.

Behavior change happens all the time - typically not as a result of deliberate planning or intentional initiatives but more often as unintended consequences of poor planning or through the introduction of new, untested procedures. At the same time, some behaviors endure, even when the original reason for them has disappeared ("because we've always done it that way"). Even when individuals, organizations, and social groups have good intentions to change their own or organizational behaviors, these intentions can go awry.

Importantly for those seeking to effect change, behaviors often occur in sequences or patterns that may need to be changed as a whole. Behavioral patterns at both the individual level (e.g., technology use) and the organizational and institutional levels (e.g., purchasing and infrastructure decisions) have significant impacts on building operational performance. Technologies in use, policies and procedures, and infrastructure (the building shell, interior walls and surfaces, layout of space, equipment, etc.) are the result of choices driven by individuals' behaviors; however, once in place, they also serve to constrain 
and channel behavior. Therefore, this study uses inclusive definitions of "behavior" and "behavior change" encompassing individuals (those with the authority and responsibility to plan or control and those who are supposed to follow directions), organizations, and institutions. Moreover, the adoption and use of technologies are inextricably intertwined with behaviors at all levels as in the common phrase, "You can't have one without the other."

Building operational performance is the measured metrics of system efficiency, sustainability, productivity, environmental quality, and functionality.

Building operational performance is considered here in two contexts. The first emphasizes energy and water use, as addressed in Executive Order 13423 (Strengthening Federal Environmental, Energy, and Transportation Management, from 2007) ${ }^{1}$ and expanded under Executive Order 13514 (Federal Leadership In Environmental, Energy, and Economic Performance, from 2009). ${ }^{2}$ In this sense, the goals are to minimize energy and water use through conservation and efficiency, and to increase the use of renewable types of energy and products. The second relates to sustainability, as per Executive Order 13514. In this sense, building operational performance includes an emphasis on energy, GHG emissions, and water use efficiency, but adds other sustainability goals such as waste minimization, pollution reduction, and information technology management.

Given these definitions, it follows that behavioral change in buildings must be addressed at multiple levels within the context of organization. The behavior of individuals in the organizational context is governed by the formal (explicit) and informal (implicit) expectations, rules, and regulations of the employment contract. The success of organizations in meeting their goals depends on effective application of the knowledge, skills, and abilities of individuals in their roles. As organizations continually evolve to meet internal challenges (e.g., expansion, contraction, reorganization, new products/services) as well as external challenges (e.g., regulation, legal requirements, societal imperatives, competition), strategies must adjust to address these changes.

When behavioral and institutional modifications produce persistent change, the tenor of the organization changes, enabling it to establish and meet more ambitious sustainability goals as time goes on. Studies of major firms that have succeeded in implementing behavioral change (e.g., Prindle 2010, Duhigg 2012) show that not only are employees enthusiastic about devising ways to save energy, but also that such efforts spur innovation in a broader range of improvements to business processes. In addition, agencies gain a deeper understanding of their own culture and effective pathways to cultural change (Haanaes et al. 2011).

Institutionalizing these types of changes can help agencies build upon and adjust their use behavior strategies, in contrast to launching a series of time-limited initiatives with high expectations but shortlived effectiveness.

\subsection{Buildings as the Locus of Behavior}

Behaviors relevant to buildings occur at many levels, from individual to institutional (see Figure 3.1). Inside a building there may be open spaces with cubicles and reception areas, a cafeteria, conference

\footnotetext{
${ }^{1}$ http://www.gpo.gov/fdsys/pkg/FR-2007-01-26/pdf/07-374.pdf

${ }^{2} \mathrm{http} / / / \mathrm{www}$.whitehouse.gov/assets/documents/2009fedleader_eo_rel.pdf
} 
rooms, hallways, stairways, restrooms, and elevators. The uses of these spaces can range widely: work processes, product development, meetings, social gatherings, and housing energy/water/mechanical systems (including lighting, heating, cooling, and ventilation). Building spaces must accommodate equipment (copiers, printers, telephones, vending machines), staffing changes, food and drink consumption, restroom comfort stations, and getting around (in and out of the building, to and from interior spaces).

The intent behind designing and operating buildings, of course, is to support an agency's work and mission. Any environmental goals should aim to provide this support in a sustainable way. When Federal managers and staff talk about building performance, therefore, the fundamental purpose of the building must be constantly kept in mind, and ideally explicitly linked to actions taken.

The everyday uses of space and equipment affect a building's overall performance. Building system data can be used to detect performance changes in building systems, internal and external building environments, and the use of spaces and systems in the building. The data can identify use patterns of the occupants as well as interactions among building systems and between those systems and the environment (see also Appendix A).

Behaviors also affect a building's overall performance and the ability of its hardware and mechanical infrastructure to achieve resource and environmental objectives through the decisions people make and how they select, use, and maintain the building and its infrastructure (hence the gap between "as designed" and actual building performance (Turner and Frankel 2008)). Likewise, the office equipment, policies, and procedures that organizations use result from individuals' decisions, and require people to select, use, maintain, and interact in ways that serve their business needs or mission.

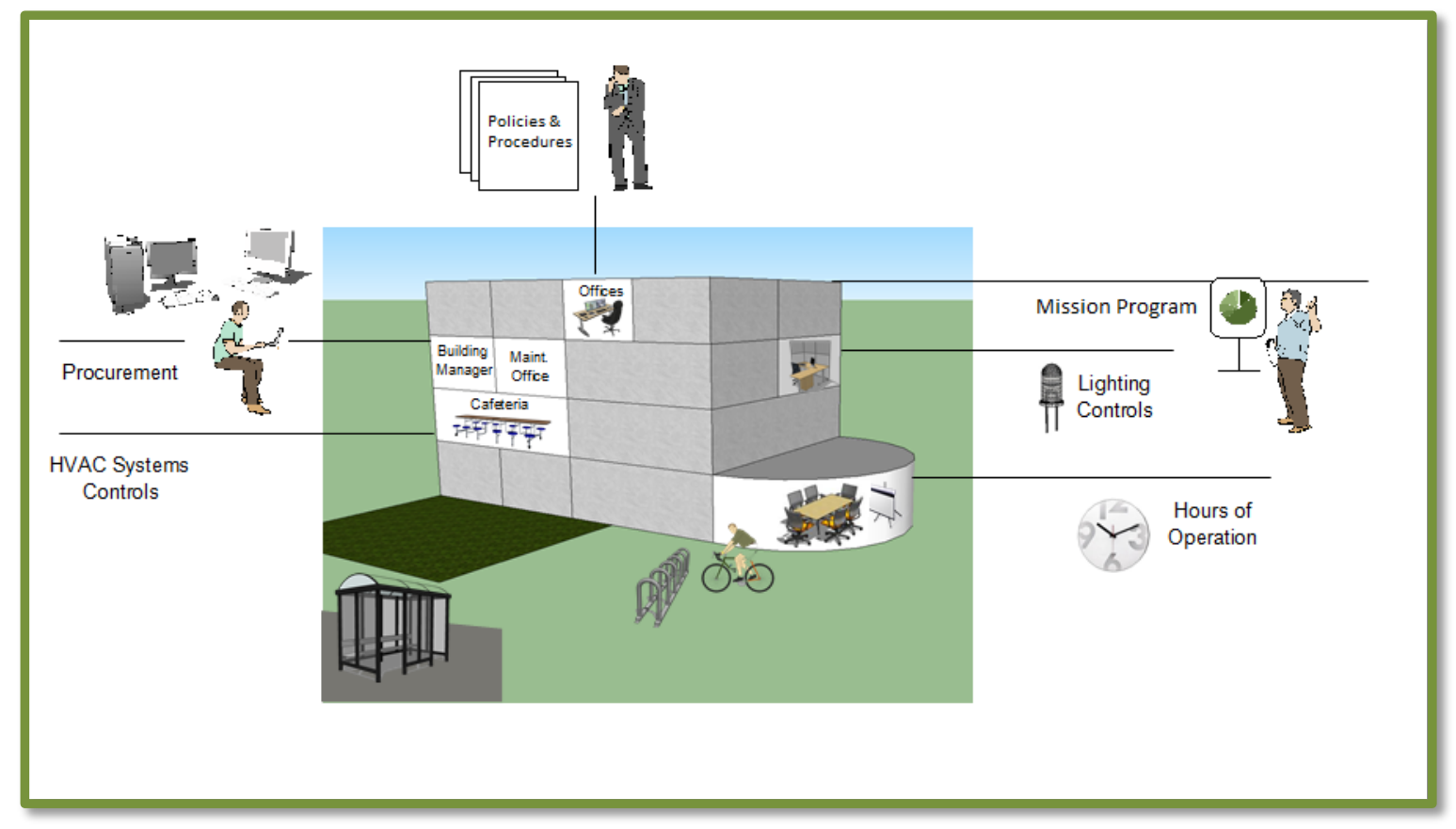

Figure 3.1. Building Resource Use is Influenced by Occupants, Systems, Infrastructure, and Organizational Rules 


\subsection{The Dynamics of Occupants in Buildings}

Buildings are complex systems, and so are the social and organizational activities within them. Building occupants, who are assigned building space or authorized to use its services, need tools and an environment to help them do their jobs - comfort and food services, adequate lighting, and ventilation and to interact with other building occupants, and may have set work patterns or highly irregular and unpredictable schedules and duties.

An institution may establish rules for hours of operation as well as for conditions of vacancy (e.g., telecommuting arrangements, travel). Building owners and managers typically use infrastructure and equipment to provide adequate working conditions, amenities, and comfort. Procurement staff may acquire equipment and supplies (e.g., paper, toner, batteries) to support occupant needs and well-being. Decisions and actions may be based on formal directives or informal practices (e.g., if high-level managers complain about ambient temperature, energy or facility managers are likely to make adjustments, regardless of the energy/performance implications). And, the specifics of all of these elements may change over time.

Thus, sustainability and building performance objectives may influence, but not necessarily determine, what decisions are made or what actions are taken. This dynamic environment necessitates a flexible and evolving approach to aligning occupant use behaviors with building functions, services, and systems over time. 


\subsection{Rules, Roles, and Tools: Using Knowledge of Institutional Context as a Basis for Taking Action}

The complex and dynamic world of human behavior and behavior change affects both the performance of and the demands on Federal and commercial office buildings. The three elements (rules, roles, and tools) outlined in this paper help to frame the evidence-based insights and actions that drive significant and enduring reductions in energy and resource use. These elements provide avenues for understanding the institutional context within which improved building performance is to be achieved (see Figure 4.1). Viewing organizations and building performance through the lens of rules, roles, and tools provides a basis for selecting potentially effective strategies to spur and maintain desired changes. From this standpoint, behavior and behavior change help to enable desired outcomes; they are neither ends in themselves nor mandated by Federal requirements.

The construct of "rules, roles, and tools" can help to structure an Action Plan for Behavior Change to achieve sustainability and building performance goals. Briefly, the terms can be described through the questions they address:

- Rules: What are the policies, procedures, and norms that support the present behaviors and the principles that apply to changing those rules?

- Roles: What/whose behavior matters with regard to that problem? What needs to change?

- Tools: What technologies, processes, and systems are in place or needed to support desired behavior changes and outcomes?

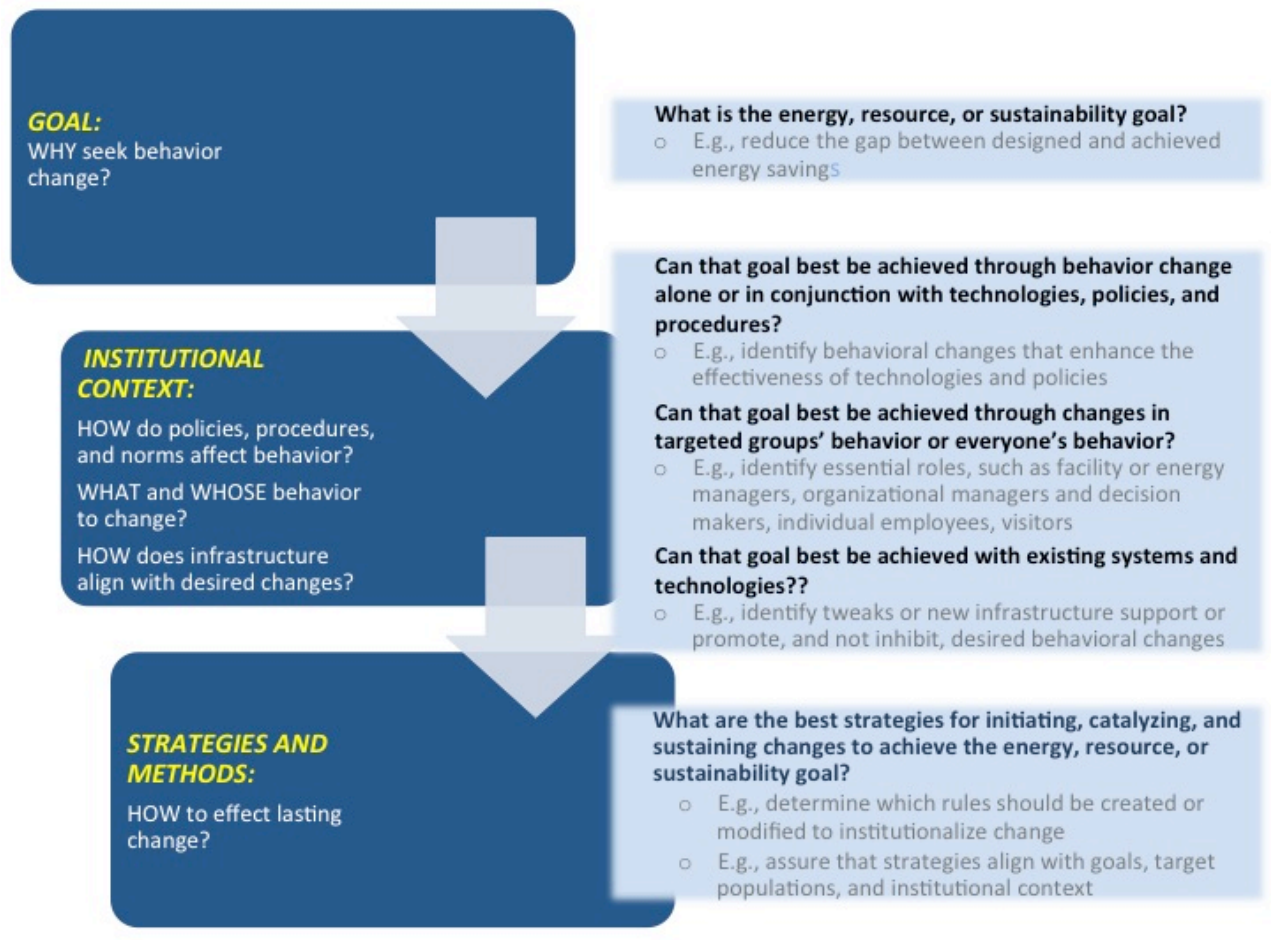

Figure 4.1. Process Diagram for Identifying Institutional Change Elements (Rules, Roles, and Tools) that will Drive the Selection of Strategies for Achieving Change Goals 
Rules, roles, and tools are inextricably linked and are key components of institutional context. It is crucial to understand both the formal and informal rules that shape the way organizations and individuals within them operate, whether those rules take the form of formal executive orders establishing Federal agencies' sustainability goals; procedures for maintaining a building's mechanical equipment; or more informal, tacitly accepted ways of doing business. New or modified rules may constitute effective methods for ensuring that sustainability-oriented behaviors endure in organizations, outlasting staff turnover and dimmed recollections of why formal or informal rules exist. It also is essential to identify categories of people within organizations who have the authority to effect change or whose behavior (role) is critical to the success of a technology or policy. At the same time, revising job descriptions is among the straightforward strategies available to initiate lasting change in organizations. Tools, then, are the technologies, processes, and systems that constitute an organization's infrastructure. That infrastructure may serve to enhance or inhibit behaviors that align with sustainability goals. As an example, procurement systems may be designed in ways that make it easy—versus difficult — to select "green" products (and hard not to select such products). Similarly, easily accessible duplex printers are essential for complying with directives to reduce wastes by printing on both sides of paper.

Once an organization's rules, roles, and tools are assessed, it is possible to select suitable strategies and tactics for achieving and sustaining change in organizations. It is vitally important to select strategies and tactics that align both with energy or sustainability goals and with the institutional context of an organization (rules, roles, and tools).

In taking this institutional context approach, rules, roles, and tools distinguish among sustainability and performance goals, building-related O\&M challenges, and key players, parties, and strategies. Mapping the building ecosystem in this way reduces the complexity of this seemingly intractable concept called "behavior" or "behavior change" and specifies ways in which evidence-based, proven approaches can make a difference.

Importantly, significant and persistent change requires multiple interventions at multiple levels over time - that is, changes relevant to rules, roles, and tools - as the extent to which change needs to be supported by other changes becomes known and feasible. Heath and Heath (2010) point out that "moving change forward is best accomplished by searching for both successes and problems, then using the successes to overcome the problems." This insight provides a simple construct to help identify a path forward - using in situ successes and failures in the dynamic building environment.

Setting a clear goal is the first step in the process of achieving higher-order sustainability goals. Once the goal is established, it is important to assess the institutional context within which that goal is to be achieved. In the section below, we delineate the rules, roles, and tools components of institutional context, providing specific examples.

\subsection{Rules}

Individual, group, and institutional rules, both formal and informal, directly influence occupant behaviors and must be identified and addressed.

Action: Identify the formal and informal rules that support current behaviors targeted for change and that influence the organization's ability to achieve the specified sustainability goal. 
Formal and informal rules shape behavior in the workplace, establishing what constitutes preferred, acceptable, and unacceptable actions. Formal rules can be interpreted in multiple ways. In practice, it is the informal rules that often determine how formal rules are interpreted and, should multiple rules apply, which rules actually should be followed.

Rules also can be used to prompt and reinforce sustainability-oriented behavior changes. For instance, short-term change may be achieved through strategies such as campaigns, competitions, and training. But for change to "stick" and sustainability goals to be achieved over the long term, new behaviors must be supported by new rules. Such rules include policies, procedures, and informal practices. Initial efforts to identify needs for new rules or modifications of existing rules should be goal-oriented, linking to resource-use or GHG reductions; and context-specific, taking into account—and, ideally, having neutral or positive impacts on-mission and job responsibilities.

Example: In a situation where the goal is to reduce the gap between designed and achieved energy savings, one might ask about the actual maintenance schedule, known operating problems, and observed occupant behaviors (e.g., leaving exterior doors open, blocking vents, using individual coffee pots or space heaters). After diagnosing the problems, a planner or analyst can identify appropriate adjustments. Leaders can alter policies or practices, and lead by example, e.g., by visibly engaging in conservation activities or actively communicating new procurement procedures. Can defaults be reset on computers, printers, and other office equipment in ways that occupants see as contributing to, rather than impeding, their ability to do their jobs? Can building policies be changed? Can communal devices such as coffee pots or refrigerators be made more appealing to use as substitutes for multiple personal devices? To analyze and determine effective change options, a review of formal rules needs to be supplemented by dialogue with people who represent critical-path roles and who may be most affected by altered policies, technologies, or practices. This dialogue can identify non-obvious rationales for behaviors and habits, and thus may lead to potentially effective strategies for creating and promoting new habits. The effectiveness of these strategies then can be tested.

Evidence: Smith (2005) suggests that managers should alter the environment, context, or infrastructure to make change easier than continuing old behaviors. Managers should problem-solve with staff and remove barriers and change-conflicting policies and procedures (Goins and Moezzi 2011, 2013). Prindle (2010), in his studies of successful energy-efficiency efforts in firms, reiterates that firms identify staff involvement as an essential element to effecting change.

\subsection{Roles}

It is important to determine the roles that are essential in achieving a goal and who, in which roles, can effect change that will solve the problem.

Action: Analyze who is essential and who can make a difference in a specific problem area.

Example: If the problem goal is to shrink a documented gap between as-designed or benchmarked energy use and higher actual energy use, it will require several categories of people to help close that gap (Cole 2011). Examples include the following: 
- Building managers and O\&M staff, who have perhaps the largest role in saving energy: they know the building systems and can uncover technological issues and observe occupant behavior that works against reduced resource use.

- Occupants, who, in the course of performing their jobs or using buildings, may increase resource use by resetting temperature controls, blocking vents, adding personal small appliances or lights, and so on. Because of the focus on occupants in many sustainability programs, there are many potential behaviors that could be changed. However, it is important to make sure that (1) occupants can control resource use in the ways specified ("tools"); (2) their legitimate needs for comfort, indoor air quality, and lighting are achieved; (3) their job-related needs are met; and (4) new or modified behaviors become embedded as "normal" so that they persist and remain effective as situations change (e.g., new responsibilities, technologies, or staff members).

- Leaders, from top management to staff champions, who visibly advocate and set examples of energysaving behavior. Leaders and champions may overlap with other roles.

- Managers and technical representatives, who approve purchases and thus can specify ENERGY STAR ${ }^{2}$, Federal Energy Management Program-approved, or other resource-efficient products. These individuals may have the authority to limit the number and types of personal equipment, as well as the (sometimes conflicting) responsibility to provide workspaces that enhance productivity and comfort.

- Contracting officers and procurement personnel (i.e., major "back office" players on the actual products and services purchased), who can also limit their purchases to those that conform to energy, water, materials, and indoor air quality standards.

- Information technology specialists, who can set defaults for "sleep" modes, double-sided printing, etc., and encourage overnight shutdown of equipment (e.g., by applying patches at start-up or shut down), while assuring these practices align with other organizational responsibilities (e.g., cybersecurity).

- Administrators who set building policies such as hours of operation, lighting protocols, and office assignments (taking into account such factors as occupancy rates).

It is extremely important to differentiate the roles that are involved in the behaviors targeted for change, and to engage the pivotal roles first - those with the leadership, authority, resources, and influence to initiate and maintain changes that will lead to reaching sustainability and building performance goals, as well as those whose "buy-in" is necessary. Once pivotal roles are aligned and individuals are motivated, a comprehensive change program can be developed (Gardini et al. 2011).

Evidence: The literature on organizational change (e.g., Aiken and Keller 2009; Harvard Business Review 2011, 2001; Kotter 1996; Argyris and Schon 1996; Lewin 1951) emphasizes that multiple roles and levels need to be involved to both effect change and to institutionalize it. Smith (2005) finds that asking people to do something they cannot do makes the situation worse.

\subsection{Tools}

It is essential to assure that the organization's infrastructure is in alignment with the behavioral changes necessary for achieving sustainability objectives. 
Action: Assess the degree to which existing technologies, systems, and processes support or inhibit the ability to achieve sustainability and energy-use goals.

Example: Continuing the example above, knowledge assembled about rules and roles - especially when gleaned from dialogue with relevant staff — can help to identify the extent to which the organization's infrastructure needs to be tailored to effect behavior changes. Only when tools are appropriate and properly aligned with goals, rules, and roles can they effect and sustain change. Examples include revising maintenance practices or other standard operating procedures, recommissioning buildings, embedding specific energy-efficiency requirements within procurement procedures, and optimizing equipment settings and operation. Other tools reflect changes in how business is conducted a new rule to discontinue the use of space heaters could be combined with infrastructure changes such as a new process through which building managers improve comfort levels or the installation of new occupant-responsive technologies. Coupling these tools to promote both short- and long-term change can help ensure that sustainability successes persist once they are achieved. If formalized rules (e.g., prohibitions on individual space heaters) and standard operating procedures (e.g., timely responses to complaints about discomfort) are enacted, rules can become tools.

\subsection{Strategies to Prompt and Sustain Change}

It is essential to identify which strategies are best-suited for achieving sustainability goals within the rules, roles, and tools of an organization that will best facilitate occupant behavioral changes to achieve sustainability objectives. The set of strategies that constitute the behavior and behavior change "portfolio of options" are not interchangeable; sustainability managers must carefully match strategies to situations, problems to be solved, and feasibility for users. Strategies must be selected for specific contexts to achieve specific goals over specific periods of time (e.g., how long might commitments be relevant?). A hammer and drill serve different purposes, and so do formal standard operating procedures, competitions, and real-time feedback. Likewise, just as both hammers and drills are essential in building construction, multiple behavior and behavior change methods may be necessary to achieve an enduring organizational culture of sustainability.

Some modifications to existing rules, roles, and tools are particularly suited for institutionalizing change. Examples include rewriting position descriptions and performance standards, requiring the reporting of progress toward goals, instituting required training of new rules and strategies, changing the organizational structure, and adding budget lines to highlight costs/savings or to support initiatives. These types of strategies promote a shift from implicit or short-term expectations about sustainability to explicit, long-term ways of doing business.

Evidence: Evidence-based approaches for behavioral change exist and are provided in Sections 5 and 6 , with the caveat that many have not been tested in rigorous ways in Federal or commercial office settings or for sustainability goals, or for organizations (as opposed to individuals). 



\subsection{Strategic and Specific Methods to Achieving Behavioral and Institutional Change}

This section identifies specific methods that have been used as behavioral interventions. It notes some of the virtues and limitations of different methods, including contexts in which methods may be more or less appropriate and effective. It draws primarily from the body of psychosocial literature, which seldom addresses institutional change or sustainability-related behaviors. For these reasons, this section begins with a short discussion of that literature as a whole and, throughout, identifies uncertainties and gaps in applying the findings to Federal building sustainability goals.

\subsection{About Peer-Reviewed Behavioral Change Literature}

Research on behavioral change distinguishes between interventions aimed at individuals or groups (psychosocial interventions) and those aimed at institutional policies and practices (structural interventions). While the previous section focused primarily on structural changes, this section focuses on psychosocial interventions to support and reinforce changes in policies and practices.

The different levels of focus (individual behaviors versus structural changes) derive, in part, from the academic discipline of the researchers. Cognitive and social psychologists typically focus on the mechanisms influencing action and thus tend to have tightly constricted research paradigms and relatively short time frames for conducting research. In contrast, sociologists and anthropologists generally take a broader view of behavior that links culture, roles, and other contextual factors. This paper explicitly incorporates both approaches as necessary to achieve persistent change across an organization. ${ }^{1}$

The majority of research discussed in this section draws on psychological frameworks and involves mechanisms that act on individuals or small groups. Topical areas divide this section. For areas with a rich and extensive body of research, it is possible to identify best practices. For other emerging areas, such as behavioral economics (e.g., Ariely 2009; Thaler and Sunstein 2009), there is not yet a sufficient body of research on building-related behaviors to be able to identify consensus best practices. In these cases, we briefly describe what is known and its potential application to building-related behavioral change.

\subsection{Providing Information and Outreach}

Information and outreach are systematic attempts to provide important knowledge beyond standard norms to particular segments of a community, with the intent of initiating change.

Information and outreach efforts are among the most common approaches to encouraging behavior change and have been widely used in public health campaigns (Campbell et al. 2000) and in initiatives oriented toward home energy use (Abrahamse et al. 2005). As in the public health arena, information and outreach often are used in the hopes of prompting individuals (as distinguished from organizations) to change their behavior. Information (education) campaigns may provide general material about

\footnotetext{
${ }^{1}$ For further detail and resources, see the U.S. Department of Energy Federal Energy Management Program's Institutional Change website: http://energy.gov/eere/femp/institutional-change-sustainability
} 
environmental problems (e.g., impact of energy and water use on the environment) or may contain specific recommendations on how to save energy and water. Techniques for information and outreach include workshops, mass media campaigns, videos, and direct mail. Sometimes techniques are highly tailored, like energy audits. Providing information in various formats is usually necessary, but information alone is not sufficient to effect change (McKenzie-Mohr and Smith 1999).

Campbell et al. (2000) conducted an extensive review of the effectiveness of community-based public health interventions that used a wide range of strategies including educational sessions, curriculum development, networking and coalition development, counseling, mass campaigns, and home assessments. The review found that many of the projects were effective in increasing short-term public awareness of environmental health risks, but that few were associated with actual changes in behavior. The most successful programs used multiple awareness events and multiple settings (see Section 6.2, Appealing to Multiple Motivations).

Although information and outreach are commonly used approaches, they may not be the most effective methods for instigating or sustaining behavior change. Campbell et al., for instance, found that even if information reaches its targeted audience and affects attitudes, it does not necessarily lead to behavior change. That is, it is possible to "change minds" without changing behavior. This finding may be especially true when the specific behaviors targeted for change are well-established habits ${ }^{2}$, as noted by Verplanken and Wood (2006, p. 91), who state, "consumers' everyday lifestyle habits limit the effectiveness of interventions that do not address the performance contexts and social structural factors that maintain habits."

However, because information and outreach can successfully increase knowledge and possibly change attitudes, they may be important first steps in many behavior change programs. The Stages of Change model (Prochaska et al. 1997) uses information and outreach to increase awareness of a problem and to "plant the seeds" for change. Thus, change managers need to know what factors increase the effectiveness of outreach messaging in raising awareness.

Success factors and best practices for information and outreach messaging (remembering that success here means "message received") include reviews of successful outreach campaigns. Following are success factors and best practices for information and outreach messaging as derived from the literature (e.g., Abrahamse et al. 2005; Campbell et al. 2000) which shows messages are more likely to be seen and remembered when they:

- Provide vivid, concrete, and personalized information.

- Use credible, trustworthy sources to convey messages.

- Use clear, concise, and concrete language to increase understanding and memorability.

- Use multiple methods and settings, and deliver content over multiple sessions rather than during a one-time effort.

- Tailor the information to the specific context.

- Circulate information through social networks.

\footnotetext{
${ }^{2}$ Actions to reduce cigarette smoking are a well-known example from public health. For nearly a half-century since the publication of a pivotal U.S. Surgeon General report in 1964, there have been continuing information campaigns together with the enactment of rules pertaining to advertising and restrictions imposed in public- and private-sector establishments. These experiences attest to the (a) failure of information, knowledge, or self-interest automatically to lead to behavior change; (b) need for multiple strategies; and (c) possibility that achieving an enduring change may require long-term, continuing efforts.
} 


\subsection{Giving Feedback}

Feedback techniques provide information on how well an individual or group is performing relative to a specified goal, how current behavior outcomes compare to past outcomes, or how personal behavior outcomes compare to those of other individuals or groups.

Feedback in one form or another has been a common element of behavior change initiatives for decades, especially for residential energy use. Recently, the means of delivering feedback has expanded. Now there is the ability to see links between specific behaviors and progress toward achieving goals in real time, highlighting the integration of new technologies with social systems to provide highly accessible and immediate feedback, e.g., on a dashboard display in front of the viewer. The key challenge for feedback approaches is to use data not only to inform, but also to motivate change. Feedback by itself is only information; how people respond to the information is the focus of behavioral change efforts.

When applied to energy consumption, primarily in residential settings, feedback techniques have resulted in energy reductions of 5 to 12 percent depending upon the specific context and methods used (Froelich 2009; Ehrhardt-Martinez 2010). Furthermore, studies of continuous versus monthly feedback about energy usage show that continuous feedback is more effective in achieving reductions in energy use. Households receiving continuous feedback reduced gas use by 12.3 percent compared to 5 percent for households receiving monthly feedback (van Houwelingen and van Raaij 1989). Other studies find similar results (Foster and Mazur-Stommen 2012). In response to OPower's Home Energy Reports sent to Minnesota electricity customers, there were verified reductions of 2.10 to 2.27 percent in the first year of the program (Power System Engineering 2010). In another study (Winkler and Winett 1982) based on 19 sets of data from experimental studies, households were informed frequently (usually daily) about how much energy they were using. Study participants who modified their habits reduced their energy consumption, some by as much as 20 percent. Darby (2006) reviewed 38 studies of energy efficiency and found that feedback reduced energy usage by 10 to 14 percent on average.

Frequent or real-time feedback can now be provided through smartphone applications (apps), equipment sensors, and computer- or lobby-based dashboards, and persuasive technologies can be applied to social groups (Consolvo et al. 2009). The technologies now available may be especially useful for energy behaviors insofar as they have the potential to solve the "invisibility" problem (Froelich 2009). Because energy is invisible and untouchable, it is especially difficult to motivate behavior change and to identify links between behavior and energy use. Several technologies focus on "seeing" energy. Dashboards, for instance, can be designed to display graphs of real-time resource use of appliances, trends over time, differences between groups, and other relevant data analyses.

Other technologies show energy in a more abstract manner and are intended to send rapid and easily recognizable messages. The idea is to make energy use available when and where the user needs it without interrupting ongoing activities. For example, a lighted energy orb in one application glows green when energy use is within the desired limits, but glows red when energy use is high (Consolvo et al. 2009). This method does not indicate how much energy is being used, but whether it is within or outside set targets. Feedback on progress toward goals is a common element in many applications. These applications range from simple graphics or statements about progress to emotionally appealing rewards (Consolvo et al. 2009). For instance, a phone app related to exercise uses a garden analogy. As exercise increases (as measured by a pedometer), the display shows flowers growing. As progress toward the goal increases, more flowers appear in the garden. Another exercise-based program described by Consolvo and 
colleagues enables users to exchange information on their progress with others and to provide encouraging messages. Another activity-based application uses a desktop "statue" linked to physical activity levels of workstation occupants. When activity levels are within the set goals, the statue is upright. When activity levels are too low, the statue slumps. Although these approaches do not currently focus on resource consumption, the potential exists to provide feedback on energy or water use.

Most of the literature focuses on individual behavior and on behavior changes from which individuals derive tangible, personal benefits. However, some literature indicates that feedback also can be effective in social groups. Siero et al. (1996) combined feedback with social norms (see Section 5.8, Tapping into Social Norms below) in an experiment designed to reduce energy consumption in an office building. One test group received feedback only about its energy consumption relative to a set goal, while two other groups received comparative feedback - how well each group was doing relative to the other. The experiment was run over a 20-week period from November through March. Research methods included assessment of attitude change as well as actual energy reduction. Results showed that the comparative feedback groups were more successful in saving energy than the group that received feedback only about its own performance. Furthermore, those in the comparative groups also changed related behaviors that were not targeted. Interestingly, the experiment showed no changes in attitudes among all three groups over the study period. It also is unclear how long the observed behavioral changes would persist in the same groups, or as group membership evolves over time.

Following are success factors and methods with evidence of success for feedback as derived from the literature:

- Provide more frequent (daily, real time) versus less frequent (weekly, monthly) feedback.

- Make data available in an unobtrusive manner when and where needed.

- Combine feedback with specific actions to reduce energy consumption (or other sustainability outcomes).

- Provide feedback on how well people are doing, such as progress toward goals and goal achievement.

- Reinforce or reward successful resource-saving behaviors, which can include verbal praise or visual methods that translate impacts of behavior into environmental benefits (more trees, growing gardens).

- Combine feedback with prompts, reminders, or other triggers to help promote and maintain desired behaviors.

\subsection{Persuading}

Persuasion is the influence of beliefs, attitudes, intentions, motivations, or behaviors. Persuasion techniques go a step beyond information and outreach in that they explicitly aim to convince people to take certain actions. With persuasion, there is no assumption that "the data speak for themselves" (i.e., that information will lead to action).

Persuasion methods seek to convince people to change their behavior more explicitly than either information or feedback. One well-recognized source on persuasion and behavioral change is Robert Cialdini”s six “weapons of influence" (2007): 
- Reciprocity: the strong cross-cultural norm of returning favors. Can reciprocity be used to encourage resource conservation? The current focus is on competition between groups rather than reciprocity to achieve environmental goals (see the titles of numerous papers from the Behavior, Energy and Climate Change conferences ${ }^{3}$; also Metzger et al. 2011).

- Commitment and consistency: the tendency to honor an idea or goal that has been committed to orally or in writing, even if the original incentive is removed. Commitment strategies have been used since the 1970s oil embargo to reduce energy consumption.

- Social proof: the tendency for people to do things others are doing. This driver relates to social norms and conformity to group behavior. Social norms are increasingly used to generate behavioral change in organizations and communities.

- Authority: the tendency to obey authority figures, which is relevant to organizational change and the role of leadership in motivating and sustaining change.

- Liking: the tendency for individuals to be easily convinced by people they like, which is relevant to the selection of "messengers" in a behavioral change program.

- Scarcity: in marketing research, scarcity tends to generate demand ("limited time only"). Of relevance here is how scarcity of environmental resources can be used to diminish demand and lead to more efficient use (such as reduced electrical use during high-demand periods).

\subsection{Offering Rewards and Incentives}

Rewards and incentives serve to induce or motivate behavioral change.

Rewards and incentives have been frequently used to motivate and sustain behavioral change, from tokens for bus ridership to coupons for purchasing green products. Several recent projects illustrate the value of incentives. Project Porchlight ${ }^{4}$ (run by One Change, a nonprofit organization in Ottawa, Ontario, Canada) uses social networks to distribute compact fluorescent light bulbs (CFLs) and encourage households to change their behaviors. In another activity, McKenzie-Mohr and Smith (1999) sent a pamphlet on energy conservation to two groups of homeowners. One group in their study received a shower flow restrictor along with the pamphlet; the other group received just the pamphlet. Homeowners who received the shower flow restrictor were more likely to engage in the other conservation actions mentioned in the pamphlet (e.g., reducing the temperature on their hot water heaters, installing setback thermostats, and cleaning their furnaces). The CFLs and shower flow restrictor programs are also examples of Cialdini's "reciprocity" principle in which people who receive a favor or gift feel socially bound to reciprocate in some way.

A careful selection of items that serve as rewards or incentives is important; some may have the unintentional effect of demotivating the people they are designed to motivate. Monetary awards, for instance, are not motivating in the ways that people often assume. Pink (2010) and Ariely (2009), for example, describe situations in which people will be motivated to work hard without monetary compensation because of friendship ties, the ability to be creative, or their belief in a larger cause.

\footnotetext{
${ }^{3}$ See http://peec.stanford.edu/events/2011/becc/ and http://peec.stanford.edu/events/2010/becc/ for the most recent conference papers.

${ }^{4}$ See http://www.projectporchlight.com/.
} 
However, offering the same people money places the relationship on a business level — in which case, compensation can seem inadequate and demotivating. Pink suggests that money may act as a disincentive for creative, versus mundane, tasks. Ariely points to the difference between social (familial, friendship, romantic, in-group) norms and market norms; when they collide, "trouble sets in" (Ariely 2009, p. 71). Ariely also reports on an experiment in which people who performed the same task were more productive when unpaid than when paid, just as lawyers are more willing to take on pro bono work than poorly paid (albeit paid) work.

\subsection{Changing Defaults, Nudging Choice, and Enabling Adaptive Comfort}

Changing defaults - How building space is configured and how options are presented can make huge differences in the choices people make.

Sustainability can be promoted through good choice architecture — organizing a context in which people make decisions and shaping the range of behavioral options available to them (Thaler and Sunstein 2009). The concept of choice architecture was developed with reference to decisions that individuals may make in their own self-interest, such as healthier dietary choices, greater retirement savings, and the like. When applied to the realm of energy or sustainability, there is an attendant shift from individual selfinterest to organizational or national interest. The idea is to encourage people to make choices that, in the case of this paper, achieve Federal sustainability objectives. In this context, "default" options have been the predominant method used to create or alter choice architecture. Examples of default options are preset thermostat settings and the order in which "green" supplies are presented in procurement software.

Identifying "appropriate" or effective default settings may require assessment. For instance, the default settings of the physical environment can either promote or hinder energy-saving behavior. They need to make sense in the physical and workplace contexts in which they are used; a single default setting may be inappropriate for an entire building or organization. For example, the same temperature setting may result in different levels of comfort on north- versus south-facing sides of buildings or in workspaces where occupants are sedentary versus active. Building managers also can widen the default temperature range and give occupants leeway to adapt. Advantages accrue in lower energy demand, higher staff satisfaction, and ease of operation. (Buildings/people are complicated enough that attempts to narrowly control temperature may often work poorly.)

Similarly, automatic lighting controls that go on when people enter daylit spaces can waste energy. In these settings, a more effective default practice may be to provide the option to turn on the lights but have automatic controls turn them off when people leave the room (although people who turn lights on may be more likely to remember to turn them off).

Another example of choice architecture through default options involves purchasing decisions. If energy-efficient products are the default selection, rules could be enacted that would require a purchaser to justify making a non-sustainable choice. This approach is markedly different from one in which

sustainable items are an option merely identified by word or icon in a product catalog. Choice architecture can also play a role in new equipment decisions; in 2007, Walmart placed CFLs in the most visible, central, and accessible positions on its shelves and thus encouraged sales of energy-efficient products (DOE 2009). 
Moezzi (2009) discusses an interactive process of "adaptive comfort," which provides more choices for people to adjust their behaviors or the environment as they desire. Adaptive comfort could include mobility supports (laptops, wireless connectivity, mobile phones, etc.) that enable people to move to different spaces as work or comfort needs change. It also provides more choices within individual workstations, such as control over ceiling lights, task lighting, and ventilation.

Researchers with the Center for the Built Environment at the University of California, Berkeley, report on developing and testing technologies to support adaptive comfort needs (Zhang et al. 2009). These technologies include small energy-efficient fans and hand- and foot-warmers designed to condition the body envelope, while enabling ambient temperature conditions to fluctuate depending upon external weather conditions. In a laboratory test chamber, researchers found that they could maintain comfort levels across a wide range of temperature conditions, from 64 to 86 degrees Fahrenheit. They also projected potential energy savings of up to 40 percent from reduced ambient heating and cooling loads.

Beyond the few illustrations presented here, it would be useful to rethink how options are created and implemented in buildings through physical design, building operation and maintenance, and workplace procedures and practices - individually and interactively. Examples range from the location of doors, stairs, and elevators to the use of light at night for security and cleaning purposes. For instance, the design and location of stairways strongly influences whether people will choose to use the elevator or the stairs (Nicoll 2006). For energy (and health) purposes, encouraging building visitors and occupants to use the stairs may be highly desirable.

\subsection{Gaining Commitment}

Commitments are oral or written pledges to change behavior.

Commitments have long been used as methods for instigating behavioral change. Such commitments are often linked to specific goals, such as decreasing energy use by a certain percent (Abrahamse et al. 2005). A study by Katzev and Johnson (1984) analyzed the impact of commitment on home energy use. Households in the study who signed a commitment to reduce their home energy by 10 percent saved more energy than the control group. A similar study assessed the effectiveness of public versus a private commitment (Pallak and Cummings 1976). The households in the public commitment group saved more energy than those who made the private commitment or who were in a non-commitment control group, and the behavior was sustained over six months.

In another experiment, home assessors in California were trained to make use of commitment strategies and persuaded three to four times as many people to elect to retrofit their homes compared with other home assessors. The commitment-trained assessors sought verbal commitments from householders: for example, an assessor might ask a homeowner when he or she anticipates having a weather-stripping project completed and suggest a call around that time to gauge progress and/or offer help (Hirst 1984, cited in McKenzie-Mohr and Smith 1999).

Public commitments are especially powerful, because they activate social norms of commitment to others and may also activate reciprocity norms and values. However, the degree to which they engender lasting change remains unknown. 


\subsection{Tapping into Social Norms}

Social norms are the explicit or implicit rules specifying what behaviors are acceptable within a society or group.

Social norms spur and guide behavior. As a social species, humans are programmed to want to be accepted by peers and to conform to their behavioral practices. This concept has been increasingly used in the environmental field in interventions designed to reduce energy consumption and to increase recycling. In some cases, these interventions use information or feedback to reveal otherwise hidden norms to promote desired behaviors. In other cases, appeals to social norms have been used as ways to guide people to make desired choices in situations where they otherwise may not know what to do. However, research has shown that the social norms approach is not always successful and that reactions vary when people learn that their behavior is different from the norm.

For instance, in research on residential energy use, households received bills showing their energy consumption compared to others in their neighborhood (Schultz et al. 2007). Households that were above the norm tended to reduce their consumption; however, households below the norm tended to increase their use. This latter behavioral response clearly increased conformance with the average consumption, but it was also undesirable and constituted a "boomerang effect." Researchers then added another condition to see if they could reverse the boomerang effect and maintain the lower level of consumption among the households who used less energy than the norm. To do so, they added a visual communication element to bills intended to provoke an emotion-based behavioral response. Smiley-face emoticons were placed on the bills of households that were below the norm, while households that were above the norm received bills with frowning face emoticons plus hints on how to save energy. The faces were intended to provide a message of social approval or disapproval - what Cialdini (2007) refers to as an "injunctive" norm. The research showed that households that received the frowning face significantly reduced their energy use compared to the baseline; households that received the smiley face maintained their higher levels of conservation and did not regress toward the norm.

In another example, Griskevicius et al. (2008) studied the use of towels in hotel rooms. These authors point out that, when a situation changes and people do not know what to do, they look to others for evidence of how to act and will be attentive to examples of new behaviors, especially if those behaviors are specific to the changed situation. They found that guests who received a sign saying that the "majority of hotel guests in this room reuse their towels" (italics added) were more likely to reuse towels than guests who received the traditional appeal to save the environment by reusing towels. The message linking towel use to "this room" was also more successful at changing behavior than a message saying the "majority of hotel guests" reuse their towels. The closer the reference group is to the hotel guest (e.g., staying in the same room), the more powerful the influence on behavior. This finding supports Cialdini's (2007) "weapon" of social proof — the tendency to mimic the behaviors of others, especially in novel or changing contexts.

\subsection{Social Marketing in Communities}

Community-based social marketing is a programmatic approach focused on barriers to and benefits of changing behavior at the community or group level. 
Another promising method combines psychological and sociological approaches with communitybased social marketing (CBSM) and is especially relevant to behavioral change in buildings.

Organizations and occupants of buildings are both communities of people and can thus benefit from methods that use a community focus. CBSM uses multiple methods to move communities toward sustainable resource use (McKenzie-Mohr 2009; McKenzie-Mohr et al. 2012). The methods commonly employed in CBSM are commitment, appeal to social norms, communications that frame and deliver the message to targeted audiences, incentives that motivate new behavior, and prompts to serve as reminders. The specific approach developed by McKenzie-Mohr (2009) identifies the barriers to and benefits of changing existing behaviors to more desirable future behaviors. This emphasis on barriers and benefits, identified through research reviews as well as public meetings, enables a program team to use different strategies to overcome barriers to change while simultaneously supporting desired new directions. The focus is on voluntary individual behavioral change, not organizational behavior change.

Gershon (2009) also uses multiple methods, including peer-to-peer support groups called EcoTeams; commitments from local governments, faith groups, and environmental organizations; and promotion of co-benefits, including more livable neighborhoods and economic development. In the long term, these strategies build community leadership and political support to sustain the changes.

A study of the effectiveness of two CBSM programs found generally high effectiveness in changing behavior, but also variability across behaviors (Pickens 2002). The "EcoTeam Program" in Deschutes County, Oregon, focused on reducing household resource consumption using the CBSM model. An analysis of the program showed that households taking part in the program significantly reduced their water and energy use and garbage output, but not their transportation behavior. In contrast, a program in Boulder, Colorado ("Go Boulder") that focused on reducing vehicular miles traveled found a six percent shift toward use of public transportation. These findings suggest that some behaviors, like household resource use, may be closely linked, but that others, like transportation, are sufficiently different that they need a specialized focus.

CBSM approaches may be especially valuable in shifting building-related energy use behaviors. Buildings and organizations within them are communities in much the same way that neighborhoods are communities. The CBSM approach provides multiple means of engaging the building occupants and incorporates their input into the selection of methods and messaging for specific audiences (i.e., roles). The approach can also be used at the organizational level to identify barriers to and benefits of changes in rules and roles.

\subsection{Responding to an Urgent Situation}

Urgency is a quality or condition suggesting immediate or pressing importance.

When people experience a crisis they deem real, they act. Juneau, Alaska, when faced with the destruction (by avalanche) of a main power line in 2008, cut its electricity consumption by 25 to 30 percent in a few weeks (see Pasquier 2011 for this and other examples of "saving electricity in a hurry"). Severe energy austerity was self-imposed by the U.S. Army bases in Japan impacted by the earthquake and tsunami in $2011 .{ }^{5}$ However, examples such as these are rare, highly situational, driven by dramatic

\footnotetext{
${ }^{5}$ Personal communication from Richard G. Kidd, Deputy Assistant Secretary of the Army (Energy and Sustainability), U.S. Department of Defense, 9/26/2011.
} 
emergencies, and not long-lived. A sense of urgency need not derive solely from catastrophes or disasters, however. Important deadlines, potential penalties, public scrutiny, economic competitiveness, and other circumstances can drive a sense of urgency. There is limited evidence that residual savings may occur if the "urgency" is reframed from one of environmental danger to lost economic opportunity (Haanaes et al. 2012). The urgency may then spur innovation, productivity, and economic thriving. A sense of urgency may be more valuable in focusing and directing change efforts than in sustaining them over time. For instance, one of the most widely used approaches to organizational change, developed by John Kotter (1996), cites "establishing a sense of urgency" as the first of eight steps for transformational change. Among the actions needed to establish urgency is "convincing 75 percent of your managers that the status quo is more dangerous than the unknown." Two barriers to establishing urgency are underestimating the difficulty of moving people from their comfort zone and risk avoidance (or as Kotter says, "becoming paralyzed by risks"). 


\subsection{Using Cross-Cutting Elements in Selecting Methods for Achieving and Sustaining Behavioral Change}

Social science literature sometimes addresses aspects of behavior change that do not fit neatly under the headings of rules, roles, and tools. This section addresses two such topics (habitual behavior and motivation) because of their underlying importance in understanding, designing, and implementing behavior change interventions that enhance overall building performance. It also discusses the persistence of behavioral change, understanding the difficulties in evaluating such changes and their energy- or sustainability-related impacts over long periods of time.

\subsection{Establishing Habits that Foster Sustainability}

Habits are actions or activities that are carried out automatically, with little conscious effort, and are often cued by factors in the environment.

The vast majority of everyday behaviors are habitual, automatically triggered by contextual cues (locations, previous actions) that fall below the level of conscious awareness (Wood and Neal 2009). Many of the behaviors of interest to this paper - especially energy, water, and technology use - are likely to be strongly habitual. As noted by Wood and Neal, "In daily life, the tendency to act on habits is compounded by everyday demands including time pressures, distraction, and self-control depletion." Although difficult, undesirable habits can be broken; they will be replaced by new habits as soon as the context provides consistent, regular cues to support new actions. A compounding difficulty is that people have a limited pool of willpower to draw on, so enabling conditions are needed. The challenge here is to break unsustainable habits and replace them with pro-environmental alternatives, and then to support the new habits with suitable cues (Duhigg 2012).

Importantly, individuals' habits change as contexts change. Because habits are cued by context (physical environment, the social-institutional environment, existing policies and procedures), a change in the context provides an opportunity to intervene in creating new habits (Goins and Moezzi 2011, Verplanken and Wood 2006, Wood and Neal 2009). Moving to a new or renovated building, for instance, could provide the opportunity to intervene and shift habits by using many of the methods described in this study, from goal setting and commitment to rewards and motivation. Wood and Neal identify several conditions that are most conducive to forming new habits:

- A stable context in which the behaviors are performed frequently

- Rewarding behavior - in early habit formation, greater rewards lead to repetition of the behavior (necessary to create a habit)

- Behavioral reminders in strategic locations, such as recycling signs at trash cans

- Goal setting to increase the intention to change, which is a precursor of actual change

Habits also can change when individuals exert self-control. In a study of people's attempts to change their habits (Wood and Neal 2009), the most successful strategy was "vigilant monitoring" described as "heightened attention to and inhibitory focus on the unwanted response (e.g., thinking 'don't do it')." However, effortful self-control also involves significant mental and emotional effort to identify the 
context triggers, the full pattern of the habitual behavior, and the specific reward that reinforces the behavior, as well as the effort to maintain change.

For sustainability purposes, changes in the building or organizational context may be more promising ways to create new environmental behaviors than relying on occupants to exert individual self-control.

\subsection{Appealing to Multiple Motivations}

Motivation refers to a process that elicits, controls, and sustains certain behaviors.

Most intentionally promoted behavior change requires several stimuli, or "nudges" (Thaler and Sunstein 2009), from external sources. Psychologists view motivation as one of the key points of leverage for behavioral change. Fortunately, motivation comes in many forms.

Weber and Lindemann (2007) point out that decisions are made (1) "by the head" - calculationbased decisions, (2) "by the heart" - emotion-based decisions, and (3) "by the book" — rule-based decisions. Heffner et al. (2006) examined why people bought hybrid electric vehicles early in their introduction to the mass marketplace, since the payback period was so long. They concluded that individuals received symbolic meaning and value from owning such vehicles (a "by the heart" decision). In a classic study of organizational culture, Schein (1999) affirms the value of demonstrating that desired changes reinforce existing assumptions about the way to act. In an analysis of multiple motivations in green buildings, Miller and Pogue (2009) found that tenants in green buildings tend to feel more productive and take fewer sick days, and that public image and the recruitment of and retention of employees are enhanced in green buildings.

Another approach to motivation distinguishes between "intrinsic" and "extrinsic" motivators. Intrinsic motivation is internalized and has to do with feelings of achievement, having a sense of control over events, and doing interesting and important work (Pink 2010). Extrinsic motivators come from outside the person and include incentives such as money, public recognition, or rewards. Behavioral change methods draw on both types of motivation.

Rewards and incentives, discussed earlier, may be the most commonly used types of motivators. On the one hand, in a workplace context rewards and incentives are commonplace and, like other motivators, could be applied to sustainability-related behaviors and outcomes. On the other hand, people and organizations have jobs to do and missions to achieve. Federal sustainability goals may not be viewed as integral to those jobs or missions and in some cases may be seen either as a luxury or as a distraction. Therefore, it may be important to appeal to multiple motivations that are relevant to the fuller context of the workplace, and not just to energy efficiency, resource use reduction, or greenhouse gas emission reductions. Developing an explicit connection to job and/or mission effectiveness may be important for individual and organizational motivation; for instance, energy is a strategic resource for the U.S. Department of Defense (DOD), and natural resource protection translates easily to sustainability in many agencies. 


\subsection{Achieving Broad and Persistent Impacts over Time}

The methods and approaches discussed in this paper focus on structural changes in organizational and institutional practices and roles, as well as on deliberate efforts to change voluntary behaviors through psychosocial interventions. Although these methods are not widely used now in Federal or commercial buildings, there are pockets of experimentation occurring in the Federal sector. Translating these pockets of experimentation into ubiquitous, commonplace practice over time, within and across Federal agencies and to the private sector, involves several components.

Information sharing, through collaboration and interaction, is an important component of achieving sustainability within and across organizations - shifting it from an add-on program to how business is done. Collaboration among sustainability strategists is a means of identifying what practices and approaches do or do not work in particular settings (Laitner et al. 2009). Collaboration can facilitate and amplify change as programs are implemented and evolve, equally useful to facility or energy managers as to organizational managers. Knowledge sharing among managers and staff can accelerate the pace of change through social engagement and "swarm intelligence."

Evaluation is essential for determining the extent to which strategies prove effective in the pursuit or achievement of stated goals. Interim evaluations during program implementation, which allow mid-course corrections, may be more important in the process of transforming organizations than outcome evaluations, which retrospectively gauge results achieved. Defining appropriate metrics to use in either form of evaluation is challenging for three main reasons. First, it may be difficult to define meaningful metrics that align with goals - items that lend themselves to quantification (e.g., number of pledges made) may not correlate well with desired results (e.g., number of pledges sustained). Second, it may not be possible to attribute impacts solely to a single behavioral intervention or change (e.g., energy saved solely because of pledges). Third, the metrics themselves may influence behavior, particularly if they are associated with incentives (rewards) or disincentives.

A third component is an agency or organizational narrative that connects the agencies' missions, responsibilities, productivity, and sustainability goals. A narrative, more than a simple logical argument, makes sustainability part of a larger story, rather than something separate, isolated, or even an impediment to the important work agencies conduct. The narrative provides a full rationale for change, metrics for change, and, perhaps, a sense of urgency for the need to change. Alternative future scenarios can indicate the implications of proceeding with the status quo versus undertaking the changes necessary to move toward sustainability. 



\subsection{Testing the Rules, Roles, and Tools Construct}

A team of researchers from the Pacific Northwest National Laboratory tested the "rules, roles, and tools" construct in a project at Ft. Carson, a U.S. Army installation in Colorado (for more details, see Appendix B). The intervention focused on institutional and behavioral change to support the Army's Net Zero Energy goals for its military bases. Five buildings were selected for study. Two buildings were occupied by civilian personnel and three by military personnel.

The three-month intervention focused on enhancing the role of the Building Energy Monitor (BEM). At the time of the research, the BEMs had poorly defined roles and minimal training. The new training focused on how to conduct a walk-through energy use audit and how to support occupant behavior change. Pre- and post-intervention surveys of occupants addressed attitudes about energy use, comfort, and building perceptions.

The target behaviors were nighttime computer shutdown in all five buildings and temperature setbacks in two buildings with decentralized controls. Behavioral change methods included training BEMs on how to facilitate energy conservation behaviors (e.g., reminders to shut down computers and turn thermostats back at night, complimenting occupants when they performed the desired behaviors, addressing problems, providing reminders, and providing feedback). Bi-weekly emails, prepared by the research team for the BEMs, tracked how well each of the target buildings was performing as measured by percent of occupants complying with the computer shutdown. In addition, a letter to building occupants from Ft. Carson leadership supported the program.

Results of the intervention showed high variation in compliance with the nighttime computer shutdown across buildings. Peak compliance rates ranged from 24 percent to 64 percent. The compliance rates were highest in the two civilian buildings, compared to the three buildings occupied by military personnel. While computer shutdowns resulted in a 1 percent electrical energy savings, the research team estimated that savings of 10 percent could be attained with 100 percent compliance. The nighttime thermostat setback resulted in 1 percent savings in natural gas.

Survey results showed an increase in the percent of occupants saying they had the skills to implement energy savings, felt personally responsible for saving energy in their buildings, and believed it was important.

The intervention also resulted in an unintended positive impact. Ft. Carson personnel are currently redefining and enhancing the role of BEMs to be more pro-active in achieving the Army's net zero energy, waste, and water goals. 



\subsection{Recommendations for an Action-Focused Framework}

Sustainability and resource conservation is a process. What happens on the ground will change over time as user behavior changes, space and building utilization shifts, and organization needs evolve.

This paper has described the integrated and interacting sets of behavioral issues that are key to achieving efficiencies of Federal and commercial buildings. It has shown that, at many levels, the people who own, manage, inhabit, and use buildings determine the extent to which sustainability and building performance goals are achieved. ${ }^{1}$ It has highlighted the importance of institutional context and delineated the rules, roles, and tools components of that context. It has also described a variety of methods available to initiate and sustain lasting change, along with the evidence that supports their use in different circumstances.

Taken as a whole, this paper provides a high-level perspective on proven strategies and potential opportunities for Federal agencies and the private commercial building sector. Its "systems perspective" of occupant-use behaviors should enable broad organizational transformation in support of sustainability and reduced resource consumption that is significant, persistent over time, and able to be measured, evaluated, and documented. Following are high-level recommendations for implementing an action-based framework for changing individual and organizational use behaviors and achieving organizational sustainability and building performance goals:

1. Adopt a systems perspective to assess, design, implement, and evaluate sustainability and resource use strategies and programs as integrated technological and behavioral activities.

The tenets of behavior change in buildings encompass policymaking; regulation compliance, reinterpretation, or revision; operating procedures; infrastructural change; and individual actions. Behaviors that affect building performance are supported in part by specific building characteristics and requirements. Strategies and programs should modify applicable tenets, characteristics, and requirements in support of new behaviors that are consistent with sustainability objectives. Sustainable behaviors cultivated at the home or other non-workplace environments may also impact sustainability efforts in the workplace but must be researched further to better understand their potential.

2. Employ multiple methods and strategies that are supported by peer-reviewed scientific research as effective and aligned with specific sustainability goals and with mission fulfillment.

The methods and strategies supporting new behaviors serve different purposes and should be tailored to specific workplaces, contexts, and time frames. Employing multiple strategies instead of single, standalone strategies will better engage individuals and organizations possessing different motivations and responsibilities in the short and long terms.

3. Promote an enduring institutional transformation by evaluating outcomes to determine what strategies work best to build a culture of sustainability, what strategies are not effective and should be discontinued, and what strategies should be revised.

\footnotetext{
${ }^{1}$ This goal achievement includes the entire building life-cycle from design, specification, construction, use, operation \& maintenance, adaptation/reuse/renovation, and decommissioning and deconstruction/recycling.
} 
Behavioral and institutional changes are means for achieving sustainability goals, rather than ends in themselves. In creating a sustainability-oriented culture, people in their various organizational roles will expand on current activities and devise new strategies for conserving resources and improving the workplace sustainability goals.

\section{Sponsor social science research that will build the evidence base for behavioral and institutional strategies aimed at saving energy, water, and materials, and at operating buildings sustainably over the long term.}

This research should include carefully designed studies that incorporate monitoring and measuring, by collaborative teams of social scientists and building scientists, for 5-10 years, with periodic evaluations of the efficacy and persistence of institutionalized changes. 


\subsection{Research and Development Agenda for Institutional Change in Buildings}

While there is a growing body of peer-reviewed literature on behavioral change, many significant gaps remain. In particular, the research on behavioral change related to sustainability has focused on individual behavior and primarily for the residential setting; it remains to be shown whether this knowledge is applicable wholly or in part to social action oriented toward energy and resource efficiency in agency workplace settings and across different subpopulations (e.g., building/energy managers, organizational managers, office workers). Complicating these questions are specific issues, such as the impacts of the absence of a commonly understood definition of sustainability or inadequate training and orientation resources, and the potential of alternative work arrangements (such as telework) or collaborations of smaller office-level groups to further sustainability goals. Moreover, much remains to be learned about organizational (versus individual), persistent (versus short-term), and sustainability-oriented change. Even the track record in the commercial sector, although growing, is not substantial — and the greater emphasis on profitability is a significant difference from government settings.

The number of case studies (both anecdotal and systematic) is growing; however, success stories often do not draw on scientific theory and methods to generate an improved evidence base. Thus, more rigorous analysis and social science expertise are needed to identify what does and does not work in different contexts. The actions Federal agencies have already undertaken to meet Executive Order 13514 (Federal Leadership In Environmental, Energy, and Economic Performance, from 2009) directives provide a natural experiment that is ripe for study and analysis.

The highest priorities for an R\&D agenda, then, are to fill these kinds of gaps, such that findings can help Federal agencies take action to achieve significant, persistent, and measureable changes. In addition, an R\&D agenda for this area should:

1. Integrate behavioral, institutional, and technological aspects of sustainability-related change.

2. Design projects to test social science findings (e.g., from behavioral economics or community-based social marketing) for their applicability in Federal settings and in sustainability efforts.

3. Use established theory and research design to implement projects that include:

a. Rigorous baselining of comparable facilities and behaviors so that results can be compared

b. Standard, well-defined methods allowing for scrutiny and replication

c. Evaluation methods and dissemination approaches.

4. Develop reliable, robust measures and evaluation methods for behavioral and institutional change in Federal agencies - including established approaches such as interviews, focus groups, and surveys - paying specific attention to sampling protocols, question design, and qualitative analysis that would yield comparable and reproducible data 



\section{Appendix A}

\section{Subcommittee on Buildings Technology Research and Development}

\section{A.1 BTRD Agency Members}

- U.S. Department of Agriculture

- U.S. Department of Commerce

- U.S. Department of Defense

- U.S. Department of Energy

- U.S. Department of Health and Human Services

- U.S. Department of Homeland Security

- U.S. Department of Housing and Urban Development

- U.S. Department of Labor

- U.S. Department of Veterans Affairs

- U.S. Environmental Protection Agency

- U.S. General Services Administration

- National Aeronautics and Space Administration

- National Science Foundation

- Executive Office of the President

- Office of the Architect of the Capitol

- IDA Science and Technology Policy Institute

- Smithsonian Institution 



\section{Appendix B}

\section{Testing the "Rules, Roles, and Tools" Construct}

A research team from the Pacific Northwest National Laboratory tested the "rules, roles and tools" construct at Fort Carson, an army installation in Colorado Springs in 2013. The project focused on institutional and behavioral change to support the Army's net zero energy goals for its military bases. A full version of the PNNL report can be found at: http://www.pnnl.gov/main/publications/external/technical reports/PNNL-22824.pdf

\section{B.1 Charting the Organizational Context}

The first phase of the intervention identified the "rules, roles, and tools" that shape the context for energy conservation behaviors at Ft. Carson. This phase took about 40 percent of the project time line. The time commitment was necessary to identify personnel who could effectively support change, the specific behaviors to change, the systems and processes needed to support the change, and measurement systems needed to assess the impact of the intervention. This context evaluation also included a baseline survey, group discussions, and observations during site visits to help select target behaviors.

Through extensive discussions with Ft. Carson personnel, the team defined the key elements of the framework as follows:

- Rules -These rules included the formal policies and procedures related to energy use in the five demonstration buildings, as well as informal rules that might affect how a policy is perceived and the extent to which it is implemented. The importance of understanding both formal and informal rules is illustrated by the way occupants manage their temperature set points in one of the Ft.Carson buildings studied. While policies at Ft. Carson specify keeping thermostats at $70^{\circ} \mathrm{F}$ or below during heating season, practical thermostat and temperature calibration issues in one of the subject buildings meant that a thermostat setting of $75^{\circ} \mathrm{F}$ may have created a room temperature of only $68^{\circ} \mathrm{F}$.

- Roles - Key individuals and groups who could make the most difference in achieving energy reduction goals were identified and engaged in the intervention design process. For this demonstration project, those roles included

- occupants

- building energy monitors (BEMs)

- Ft. Carson senior leadership

- computer network personnel.

BEMs are members of the building community who

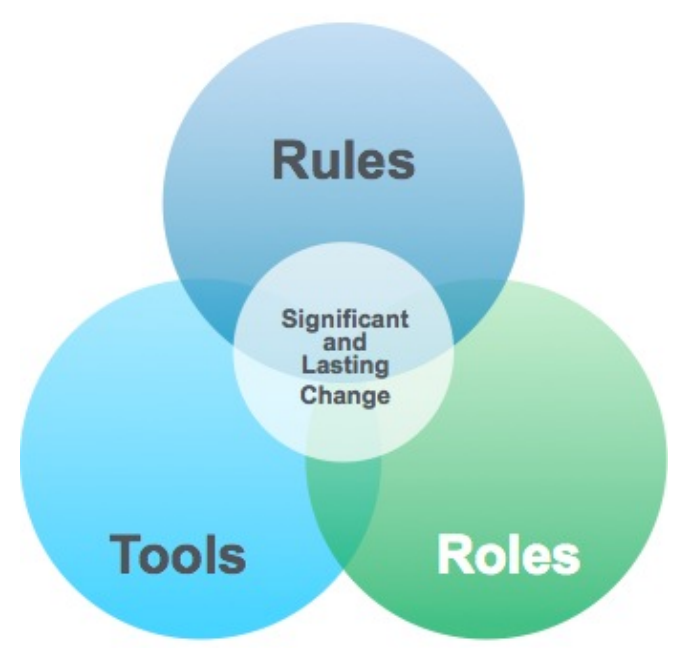


are responsible for monitoring building operations for energy-saving opportunities and reporting problems. The BEM program has been deployed Army-wide, although not all buildings at Ft. Carson have assigned BEMs.

- Tools - The research team reviewed existing technologies, systems, and processes and developed new tools that could be used to support the energy use reduction goals and help people do their jobs more easily and consistently. For example, the intervention leveraged the existing BEM to support occupant behavior change, but new tools including a floor-check form were developed by the research team to monitor key opportunities for improvement.

\section{B.2 Intervention Methods}

The intervention, which ran for three months, focused on two behaviors: (1) nighttime shutdown of desktop computers and (2) nighttime thermostat setbacks in two buildings with decentralized controls. These specific behaviors were selected because they could be easily performed by occupants and could result in a measurable impact on energy reduction.

The behavior change methods focused on enhancing the role of the BEMs to help meet Ft. Carson's net zero energy goal. Training sessions focused on conducting weekly walk through checks of the buildings and acting as a "social facilitator" with occupants (e.g., reminding them to shut down computers and set thermostat backs at night, complimenting them when they performed the desired behaviors, providing reminders, and addressing problems). Bi-weekly emails to building occupants, prepared by the research team for the BEMS, discussed the progress of the intervention, identified how well each of the buildings was doing, and provided tips for improvement (e.g., setting up "reminders to self" to shut down computers at night and turn back the thermostat.) A final e-mail on week 8 of the intervention provided a graph of the compliance with energy shutdowns in each building as well as the overall results from the weekly checks.

In addition to enhancing the BEM role, the intervention also identified actions for Ft. Carson leadership in support of the project and working with computer network personnel to enable policy exemptions on nighttime computer shutdowns and to track compliance rates.

\section{B.3 Results}

\section{B.3.1 Behavior and Attitude Change}

Results of compliance with nighttime computer shutdown showed that peak compliance rates in each building ranged from 24 percent to 64 percent. The highest overall compliance rates were in the two buildings occupied by civilian personnel.

Post intervention survey results show a greater percent of occupants saying they had the skills to implement energy savings, felt personally responsible for reducing energy in their buildings, and believed it was important. Findings also support the idea that energy change efforts may be most effective if approached as a "high touch" activity through person-to-person communications. Specific factors that respondents said had the greatest influence on their energy conservation behavior were receiving: 
- instruction from an immediate supervisor

- information on specific actions to take

- feedback on performance from a local advocate for energy conservation and,

- a letter from leadership encouraging occupants to take the specific conservation measures.

\section{B.3.2 Energy Savings}

The nighttime thermostat setbacks in the two buildings where this intervention was possible resulted in an estimated 1 percent energy savings in natural gas.

Calculation of electrical energy savings from the nighttime computer shutdowns showed a total of 1 percent savings during the intervention period. If compliance had been 100 percent, the energy savings could have been as high as 10 percent from this behavior change alone. The graph below shows the compliance rates for computer shutdown in each building over the 12 week intervention. Buildings 1118 and 1219 are occupied primarily by civilian personnel. The other three buildings are occupied by military personnel.

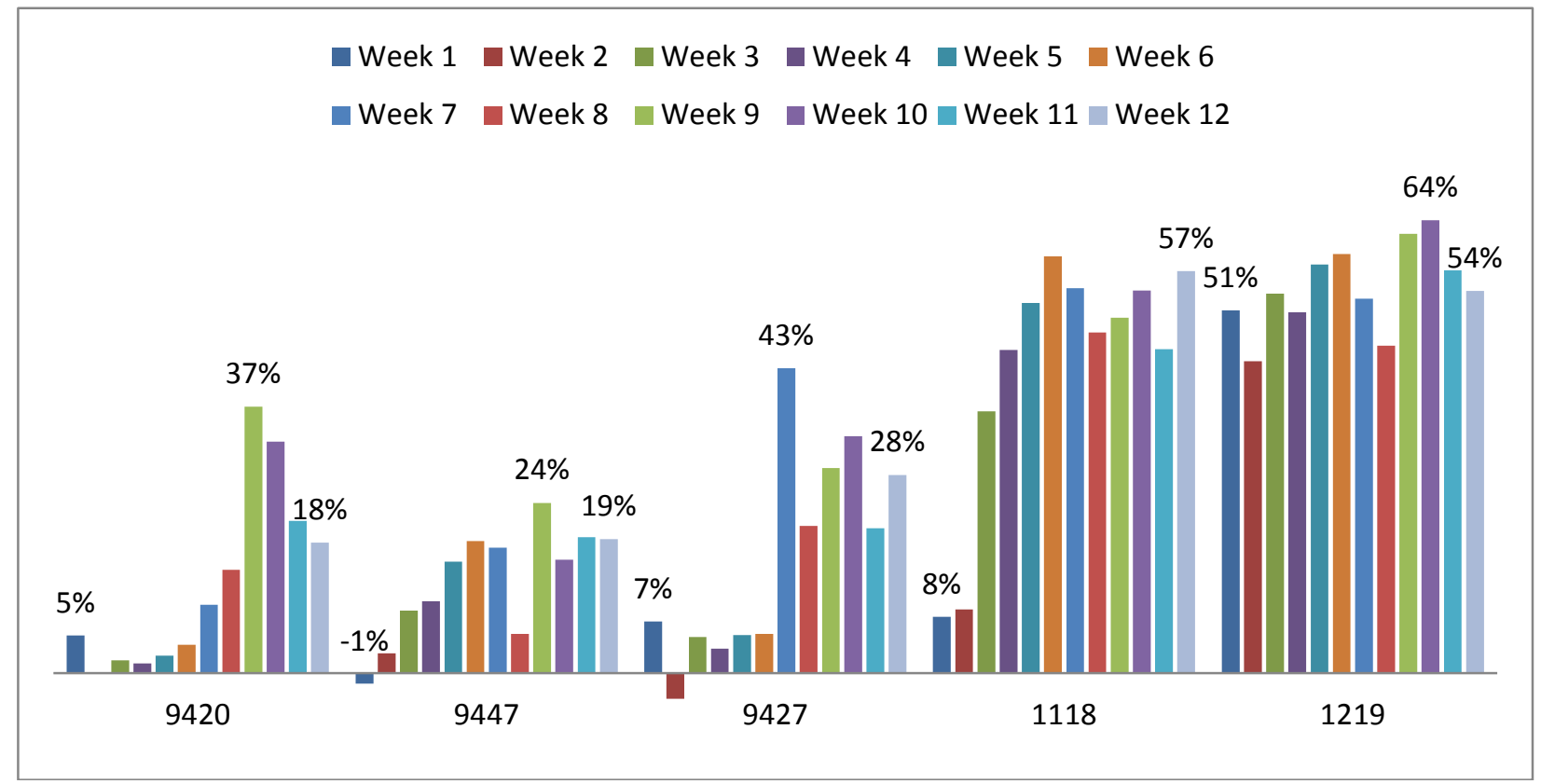

\section{B.3.3 Conclusions and Lessons Learned}

The research clearly shows that behavioral change interventions can result in energy savings. It also shows the importance of using the "rules, roles, and tools" construct through its emphasis on a criticalpath role, that of BEMs. Enhancing the role of the BEMs and providing them with training on how to interact with occupants and to encourage behavioral changes to support Ft Carson's Net Zero Energy goal was key to successful outcomes.

At the same time, this research project identified many of the challenges to behavioral change programs. Setting up the intervention was time intensive, particularly because the research team was not 
on site and needed to communicate largely by phone or email. Training BEMs remotely through a webinar limited the ability to engage in discussion, possibly decreasing the effectiveness of that training.

Despite the difficulties of putting the intervention in place and engaging with remote partners, the key indicator of the success of the rules, roles, and tools construct may be Ft. Carson's awareness that its facility management program needs to be transformed in the direction proposed by the research team. Ft. Carson currently is investigating how to implement the rules, roles, and tools construct across the installation. 


\section{Appendix C}

\section{References}

Abrahamse, W., L. Steg, C. Vlek, and T. Rottengatter. 2005. A review of intervention studies aimed at household energy conservation. Journal of Environmental Psychology 25, 273-291.

Aiken, Carolyn and Scott Keller 2009. The irrational side of change management. McKinsey Quarterly April 2009. Available at

http://www.mckinsey.com/insights/organization/the_irrational_side_of_change_management

Ajzen, I. 1991. The theory of planned behavior. Organizational Behavior and Human Decision Processes 50, 179-211.

Argyris, C., and D. Schon. 1996. Organizational Learning II. Reading, Massachusetts: Addison Wesley.

Ariely, D. 2009. Predictably Irrational: the Hidden Forces that Shape Our Decisions. New York:

Harper.

Armel, C. 2008. Energy, behavior, and design. October 28. Precourt Institute for Energy Efficiency and Stanford University.

Aune, M., T. Berker, and R. Bye, 2009. The missing link which was already there: building operators and energy management in non-residential buildings. Facilities, Vol 27 (1/2), 44-55.

Becker, L.J. 1978. Joint effect of feedback and goal setting on performance: a field study of residential energy conservation. Journal of Applied Psychology 63(4), 428-433.

Buildings Technology Research and Development (BTRD), Subcommittee on. 2011. Submetering of Building Energy and Water Usage: Analysis and Recommendations of the Subcommittee on Buildings Technology Research and Development. Washington, DC: National Science and Technology Council Committee on Technology.

http://www.whitehouse.gov/sites/default/files/microsites/ostp/submetering_of building_energy_and_wate r_usage.pdf.

Campbell, M., D. Buckeridge, J. Dwyer, S. Fong, V. Mann, O. Sanchez-Sweatman, A. Stevens, and L. Fung. 2000. A systematic review of the effectiveness of environmental awareness interventions. Canadian Journal of Public Health 91(2), 137-143.

Carrico, A.R., and M. Riemer. 2011. Motivating energy conservation in the workplace: an evaluation of the use of group level feedback and peer review. Journal of Environmental Psychology 31, 1-13.

Cialdini, R.B. 2010. Influencing Change: Applying Behavioral Science Research Insights to Reframe Environmental Policy and Programs. Sacramento, CA: Behavior, Energy and Climate Change Conference.

Cialdini, R.B. 2007.Influence: The Psychology of Persuasion, $3^{\text {rd }}$ Ed. New York: Collins Business. 
Cialdini, R.B. 2005. Basic social influence is underestimated. Psychological Inquiry 16(4), 158-161.

Consolvo, S., D.W. McDonald, and J.A. Landay. 2009. Theory-Driven Design Strategies for

Technologies that Support Behavior Change in Everyday Life. Boston, MA: CHI 2009.

Cole, R.J. 2011. Motivating stakeholders to deliver environmental change. Building Research \& Information 39,431-435.

Costanzo, M., D. Archer, E. Aronson, and T. Pettigrew. 1986. The difficult path from information to action. American Psychologist 41(5), 521-528.

Darby, S. 2006. The Effectiveness of Feedback on Energy Consumption: A Review for DEFRA of the Literature on Metering, Billing and Direct Displays. Oxford, England: Environmental Change Institute, University of Oxford.

Dietz, T., G.T. Gardner, J. Gilligan, P.C. Stern, and M.P. Vandenbergh. 2009. Household action can provide a behavioral wedge to rapidly reduce U.S. carbon emissions. Proceedings of the National Academy of Sciences 106, 18452-18456.

Duhigg, Charles 2012. The Power of Habit: Why We Do What We Do in Life and Business. Random House, New York.

Ehrhardt-Martinez, K., and J.A. Laitner. 2010. Behavior, Energy, and Climate Change: Emerging Policy Directions, Program Innovations, and Research Paths. Washington, DC: U.S. Department of Energy and Argonne National Laboratory.

Energy Independence and Security Act (EISA 2007). Public Law 110-140.

Energy Policy Act of 2005 (EPAct 2005). Public Law 109-158.

EPRI. 2009. Residential Electricity Use Feedback: A Research Synthesis and Economic Framework. Palo Alto, CA: EPRI.

Erhardt-Martinez, K. 2010. Changing Habits, Lifestyles, and Choices: the Behaviors that Drive Feedback-induced Energy Savings. Asilomar, CA: American Council for an Energy Efficient Economy Summer Study.

Executive Order [E.O.] 13514. October 8, 2009. Federal Leadership in Environmental, Energy, and Economic Performance. Federal Register 74(194), 52117-52127.

Foster, B., and S. Mazur-Stommen. 2012. Results from Recent Real-Time Feedback Studies. American Council for an Energy-Efficient Economy (ACEEE) http://aceee.org/research-report/b122.

Froelich, J. 2009. Promoting Energy Efficient Behaviors in the Home through Feedback: The Role of Human-Computer Interaction. White paper. Seattle, WA: DUB Institute, University of Washington.

Froelich, J., L. Findlater, and J. Landay. 2010. The design of eco-feedback technology. Proceedings of the 28th International Conference on Human factors in Computing Systems. Atlanta, GA: CHI 2010. 
Gardini, J., G. Giulliani, and M. Marricchi. 2011. Finding the right place to start change. McKinsey Quarterly. http://www.mckinseyquarterly.com/Finding the right_place to_start change 2890 .

Gatersleben, B., and C. Vlek 1998. Household consumption, quality of life and environmental impacts. In K.J. Noorman, and A.J.M. Schoot-Uiterkamp (eds.), Green Households? Domestic Consumers, Environment and Sustainability. London: Earthscan, 141-183.

Gershon, D. 2009. Social Change 2.0: A Blueprint for Reinventing the World. High Point, NC: Chelsea Green.

Goins, J. and M. Moezzi 2011. Case study of CalSTRS Headquarters. Center for the Built Environment, Berkeley, CA. http://www.cbe.berkeley.edu/research/pdf files/calstrs-final-2011.pdf.

Goins, John and Mithra Moezzi 2013. Linking building performance to occupant complaints. Building Research \& Information 41(3), 461-372.

Goldstein, N.J., R.B. Cialdini, and V. Griskevicius. 2008. A room with a viewpoint: using social norms to motivate environmental conservation in hotels. Journal of Consumer Research 35 (electronic version).

Griskevicius, V., R. B. Cialdini, N. J. Goldstein. 2008. Applying (and resisting) peer influence. MIT Sloan Management Review (49)2, 84-88.

Haanaes, K., M. Reeves, I. von Streng Velken, M. Audretsch, D. Kiron, and N. Kruschwitz. 2012. Sustainability Nears a Tipping Point: Findings from the 2011 Sustainability \& Innovation Global Executive Study and Research Project. MIT Sloan Management Review Special Report. http://sloanreview.mit.edu/feature/sustainability-strategy/.

Hauge, A.L., J. Thomsen and T. Berker 2010. User evaluations of energy efficient buildings - literature review and further research. In Zero Emission Buildings-Proceedings of Renewable Energy Conference 2010, Trondheim,Norway.

He, H.A., S. Greenberg, and E.M. Huang. 2010. One Size Does Not Fit All: Applying the Transtheoretical Model to Energy Feedback Technology Design. Atlanta, GA: CHI 2010.

Heath, D., and C. Heath. 2010. Switch: How to Change Things When Change Is Hard. New York: Crown Publishing House.

Heffner, R.R., T.S. Turrentine, and K.S. Kurani. 2006. A Primer on Automobile Semiotics. Davis, CA: Institute of Transportation Studies, University of California.

Janda, Kathryn B. 2014. Building communities and social potential: Between and beyond organizations and individuals in commercial properties. Energy Policy 67:48-55.

Katzev, R.D., and T.R. Johnson. 1984. Comparing the effects of monetary incentives and foot-in-the-door strategies in promoting residential electricity conservation. Journal of Applied Social Psychology (14)1, $12-27$.

Kahneman, D. 2011. Thinking, Fast and Slow. New York: Farrar, Straus and Giroux. 
Kotter, J. 1996. Leading Change. Boston: Harvard Business School Publishing Corporation.

Laitner, J.A., K. Ehrhardt-Martinez, and C.P. Knight. 2009. The Climate Imperative and Innovation Behavior: Encouraging Greater Advances in the Production of Energy Efficient Technology and Services. Berkeley, CA: California Institute for Energy and Environment.

Lenoir, Aurélie, Shaan Cory, Michael Donn and François Garde 2011. Users' behavior and energy performances of net zero energy buildings. In Proceedings of the $12^{\text {th }}$ Conference of International Building Performance Simulation Association, 14-16 November 2011, Sydney, Australia. http://www.ibpsa.org/proceedings/BS2011/P_1511.pdf

Lewin, K. 1951. Field Theory in Social Science: Selected Theoretical Papers. D. Cartwright (ed.). New York: Harper \& Row.

Lobato, C., S. Pless, M. Sheppy, and P. Torcellini. 2011. Reducing Plug and Process Loads for a Large Scale Low Energy Office Building: NREL's Research Support Facility. Las Vegas, NV: ASHRAE Winter Conference.

McKenzie-Mohr, D. 2009. Fostering Sustainable Behavior. Washington, DC: Behavior, Energy, and Climate Change Conference.

McKenzie-Mohr, D., N.R. Lee, P.W. Schultz, and P. Kotter. 2012. Social Marketing to Protect the Environment. Los Angeles: Sage.

McKenzie-Mohr, D., and W. Smith. 1999. Fostering Sustainable Behavior. British Columbia, Canada: New Society Publishers.

McKenzie-Mohr, D., and W. Smith. 2007. Fostering Sustainable Behavior: An Introduction to Community-Based Social Marketing. Gabriola Island, British Columbia: New Society Publishers.

Metzger, I., A. Kandt, and O. VanGeet. 2011. Plug Load Behavioral Change Demonstration Project. National Renewable Energy Laboratory, Golden, CO, NREL/TP-7A40-52248.

http://www.nrel.gov/docs/fy11osti/52248.pdf.

Miller, N.G., and D. Pogue. 2009. Do Green Buildings Make Dollars and Sense? Burnham-Moores Center for Real Estate, University of San Diego; and CB Richard Ellis.

Moezzi, M. 2009. Social Sciences for Reduced Energy Use in Buildings: Past Contributions and Future Potential. Washington, DC: Integrating Social and Behavioral Insights to DOE Programs and Policies.

Moezzi, Mithra and Kathryn B. Janda 2013. Redirecting research about energy and people: from "if only" to "social potential." ECEEE Summer Study Proceedings. ("Middle-out")

Moezzi, M., M. Iyer, L. Lutzenhiser, and J. Woods. 2009. Behavioral Assumptions in Energy Efficiency Potential Studies. Oakland, CA: California Institute for Energy and Environment.

Nakajima, T., V. Lehdonvirta, E. Tokunaga, and H. Kimura. 2008. Reflecting Human Behavior to Motivate Desirable Lifestyles. Washington, DC: DIS 2008. 
Nicoll, G. 2006. Taking the Stairs: Environmental Features that Explain Why People Use Stairs in 3 to 4 Academic Workplace Buildings. PhD Thesis, Georgia Institute of Technology, Atlanta.

Pallak, M.S., and N. Cummings. 1976. Commitment and voluntary energy conservation. Personality and Social Psychology Bulletin 2(1), 27-31.

Pasquier, S.B. 2011. Saving Electricity in a Hurry: 2011 Update. Paris, France: International Energy Agency. http://www.iea.org/papers/2011/saving_electricity.pdf, accessed 2/23/12.

Pickens, P.M. 2002. Community Based Social Marketing as a Planning Tool. Masters Thesis, University of Oregon.

Pink, D. 2010. Drive: The Surprising Truth about What Motivates Us. New York: Riverhead Books.

Power System Engineering. 2010. Measurement and Verification Report of OPower Energy Efficiency Pilot Program. Madison, Wisconsin: Power System Engineering.

Prindle, W.R. 2010. From Shop Floor to Top Floor: Best Business Practices in Energy Efficiency. Washington, DC: Pew Center on Global Climate Change.

Prochaska, J.O., and W.F. Velicer. 1997. The transtheoretical model of health behavior change. American Journal of Health Promotion 12(1), 38-48.

Rogers, E. 1995. Diffusion of Innovation, $5^{\text {th }}$ Ed. New York, NY: Free Press.

Schein, E.H. 1999. The Corporate Culture Survival Guide: Sense and Nonsense about Cultural Change. San Francisco: Jossey-Bass.

Schultz, P.W., J.M. Nolan, R.B. Cialdini, N.J. Goldstein, and V. Griskevicius. 2007. The constructive, destructive and reconstructive power of social norms. Psychological Science 18(5), 429-434.

Shui, Bin 2012. Greening Work Styles: An Analysis of Energy Behavior Programs in the Workplace. American Council for an Energy-Efficient Economy, Washington, DC.

Siero, F.W., A.B. Bakker, G.B. Dekker, and M.T.C. Van Den Burg. 1996. Changing organizational energy consumption behavior through comparative feedback. Journal of Environmental Psychology 16, 235-246.

Smith, J. 2005. Obtaining Behavior Change Not Just Raising Awareness. Adelaide, Australia: Australian Association of Environmental Education, SA Division Workshop.

http://www.emergingself.com.au/About_Jodi-Anne.htm.

Stern, P.C. 2002. Changing behavior in households and communities: what have we learned? In T. Dietz, and P.C. Stern (eds.), New Tools for Environmental Protection. Washington, D.C.: National Academy Press.

Stern, P. 2009. Designing Effective Policies Using Social Science Insights. Washington, DC: DOE Energy and Behavior Workshop. 
Thaler, R.H., and C.R. Sunstein. 2009. Nudge: Improving Decisions about Health, Wealth and Happiness. New York: Penguin.

Triandis, H. 1977. Interpersonal Behaviour. Monterey, CA: Brooks/Cole.

Turner, C., and M. Frankel. 2008. Energy Performance of LEED for New Construction Buildings. Vancouver, WA: New Buildings Institute. www.usgbc.org/ShowFile.aspx?DocumentID=3930.

Tversky, A., and D. Kahneman. 1974. Judgment under uncertainty: heuristics and biases. Science 185, $1124-1131$.

United States Department of Energy (DOE). 2009. Big Results, Bigger Potential: CFL Market Profile. Washington, DC: DOE. http://www.energystar.gov/ia/products/downloads/CFL_Market_Profile.pdf.

van Houwelingen, J.H., and W.F. van Raaij. 1989. The effect of goal-setting and daily electronic feedback on in-home energy use. Journal of Consumer Research 16(1), 98-105.

Verplanken, B., and W. Wood. 2006. Interventions to break and create consumer habits. Journal of Public Policy and Marketing 25(1), 90-103.

Weber, E. U. \& Lindemann, P. G. 2007. From intuition to analysis: Making decisions with our head, our heart, or by the book, appearing in H. Plessner, C. Betsch \& T. Betsch (Eds.), Intuition in judgment and decision making, 191-208. Mahwah, NJ: Lawrence Erlbaum.

Winkler, R.C., and R.A. Winett. 1982. Behavioral interventions in resource management: a systems approach based on behavioral economics. American Psychologist 37, 421-435.

Wood, W., and D.T. Neal. 2009. The habitual consumer. Journal of Consumer Psychology 19(4), 579592.

Zhang, H., E. Arens, D.E. Kim, E. Buchberger, F. Bauman, and C. Huizenga. 2009. Comfort, perceived air quality, and work performance in a lower power task-ambient conditioning system. Building and Environment 45, 29-39. 



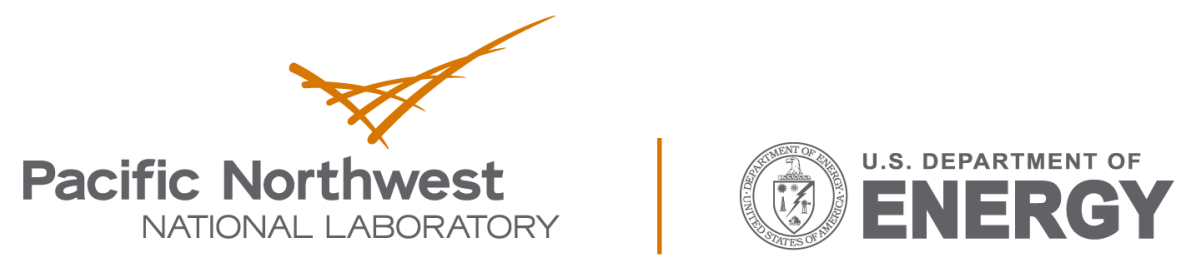

Proudly Operated by Battelle Since 1965

902 Battelle Boulevard

P.O. Box 999

Richland, WA 99352

1-888-375-PNNL (7665)

www.pnnl.gov 